\title{
2020 Korean guidelines for the management of metastatic prostate cancer
}

\author{
In-Ho Kim ${ }^{1,}$, Sang Joon Shin ${ }^{2,}$, Byung Woog Kang 3 , Jihoon Kang ${ }^{4}$, Dalyong Kim ${ }^{5}$, Miso Kim ${ }^{6}$, \\ Jin Young Kim ${ }^{7}$, Chan Kyu Kim ${ }^{8}$, Hee-Jun Kim ${ }^{9}$, Chi Hoon Maeng ${ }^{10}$, Kwonoh Park ${ }^{11}$, Inkeun Park ${ }^{12}$, \\ Woo Kyun Bae ${ }^{13}$, Byeong Seok Sohn ${ }^{14}$, Min-Young Lee ${ }^{15}$, Jae Lyun Lee ${ }^{16}$, Junglim Lee ${ }^{17}$, Seung Taek Lim ${ }^{18}$, \\ Joo Han Lim $^{19}$, Hyun Chang ${ }^{20}$, Joo Young Jung ${ }^{21}$, Yoon Ji Choi ${ }^{22}$, Young Seok Kim ${ }^{23}$, Jaeho Cho ${ }^{24}$, \\ Jae Young Joung ${ }^{25}$, Se Hoon Park ${ }^{26}$, and Hyo Jin Lee ${ }^{27}$
}

\begin{abstract}
${ }^{1}$ Division of Medical Oncology, Department of Internal Medicine, Seoul St. Mary's Hospital, College of Medicine, The Catholic University of Korea, Seoul; ' 2 Division of Oncology, Department of Internal Medicine, Yonsei University College of Medicine, Seoul; ${ }^{3}$ Department of Oncology/ Hematology, Kyungpook National University Hospital, Daegu; ${ }^{4}$ Division of Hematology/Oncology, Department of Internal Medicine, Kangbuk Samsung Hospital, Sungkyunkwan University School of Medicine, Seoul; ${ }^{5}$ Division of Hematology \& Medical Oncology, Department of Internal Medicine, Dongguk University Ilsan Hospital, Goyang; ${ }^{6}$ Division of Hematology-Oncology, Department of Internal Medicine, Seoul National University Hospital, Seoul; ${ }^{7}$ Division of Hemato-Oncology, Keimyung University Dongsan Hospital, Daegu; ${ }^{8}$ Division of Hematology \& Oncology, Department of Internal Medicine, Soonchunhyang University Bucheon Hospital, Bucheon; ${ }^{9}$ Division of Hematology/Oncology, Department of Internal Medicine, Chung-Ang University College of Medicine, Seoul; ${ }^{10}$ Division of Medical Oncology-Hematology, Department of Internal Medicine, Kyung Hee University Hospital, Seoul; ${ }^{11}$ Medical Oncology and Hematology, Department of Internal Medicine, Pusan National University Yangsan Hospital, Yangsan; ${ }^{12}$ Division of Medical Oncology, Department of Internal Medicine, Gachon University Gil Medical Center, Incheon; ${ }^{13}$ Department of Hemato-Oncology, Chonnam National University Hwasun Hospital, Hwasun; ${ }^{14}$ Department of Internal Medicine, Inje University Sanggye Paik Hospital, Seoul; ${ }^{15}$ Division of Hematology \& Oncology, Department of Internal Medicine, Soonchunhyang University Seoul Hospital, Seoul; ${ }^{16}$ Department of Oncology and Internal Medicine, Asan Medical Center, University of Ulsan College of Medicine, Seoul; ${ }^{17}$ Division of Medical Oncology, Department of Internal Medicine, Daegu Fatima Hospital, Daegu; ${ }^{18}$ Department of Oncology, Yonsei University Wonju College of Medicine, Wonju; ${ }^{19}$ Department of Hematology/Oncology, Inha University School of Medicine, Incheon; ${ }^{20}$ Division of Medical Oncology, International St. Mary's Hospital, Catholic Kwandong University College of Medicine, Incheon; ${ }^{21}$ Division of Hemato-Oncology, Hallym University Dongtan Sacred Heart Hospital, Hwaseong; ${ }^{22}$ Division of Hematology-Oncology, Department of Medicine, Korea University Anam Hospital, Seoul; ${ }^{23}$ Department of Radiation Oncology, Asan Medical Center, University of Ulsan College of Medicine, Seoul; ${ }^{24}$ Department of Radiation Oncology, Yonsei Cancer Center, Yonsei University College of Medicine, Seoul; ${ }^{25}$ Center for Urologic Cancer, National Cancer Center, Goyang; ${ }^{26}$ Division of Hematology-Oncology, Department of Medicine, Samsung Medical Center, Sungkyunkwan University School of Medicine, Seoul; ${ }^{27}$ Department of Internal Medicine, Chungnam National University College of Medicine, Daejeon, Korea
\end{abstract}

Received: October 2, 2020

Accepted: November 2, 2020

\section{Correspondence to \\ Hyo Jin Lee, M.D.}

Department of Internal Medicine, Chungnam National University College of Medicine, 282 Munhwa-ro, Jung-gu, Daejeon 35015 , Korea

Tel: +82-42-280-8369

Fax: +82-42-257-5753

E-mail: cymed@cnu.ac.kr https://orcid.org/0000-00018378-3001

*These authors contributed equally to this work.
In 2017, Korean Society of Medical Oncology (KSMO) published the Korean management guideline of metastatic prostate cancer. This paper is the 2nd edition of the Korean management guideline of metastatic prostate cancer. We updated recent many changes of management in metastatic prostate cancer in this and edition guideline. The present guideline consists of the three categories: management of metastatic hormone sensitive prostate cancer; management of metastatic castration resistant prostate cancer; and clinical consideration for treating patients with metastatic prostate cancer. In category 1 and 2, levels of evidence (LEs) have been mentioned according to the general principles of evidence-based medicine. And grades of recommendation (GR) was taken into account the quality of evidence, the balance between desirable and undesirable effects, the values and preferences, and the use of resources and GR were divided into strong recommendations (SR) and weak recommendations (WR). A total of 16 key questions are selected. And we proposed recommendations and described key evidence for each recommendation. The treatment landscape of metastatic prostate cancer is changing very rapid and many trials are ongoing. To verify the results of the fu- 
ture trials is necessary and should be applied to the treatment for metastatic prostate cancer patients in the clinical practice. Especially, many prostate cancer patients are old age, have multiple underlying medical comorbidities, clinicians should be aware of the significance of medical management as well as clinical efficacy of systemic treatment.

Keywords: Practice guideline; Prostate neoplasms

\section{INTRODUCTION}

In 2017 , the Korean Society of Medical Oncology (KSMO) published the Korean management guidelines for metastatic prostate cancer. Here, we present the second edition of the Korean management guidelines for metastatic prostate cancer, in which we have incorporated recent changes in metastatic prostate cancer management. The questions addressed in this second edition of management guidelines can be classified into three categories: (1) management of metastatic hormone-sensitive prostate cancer (mHSPC); (2) management of metastatic castration-resistant prostate cancer (CRPC); and (3) clinical considerations for the treatment of patients with metastatic prostate cancer. We addressed key questions in each category and proposed evidence-based rec-

Table 1. Definition of levels of evidence

\begin{tabular}{|c|c|}
\hline $\begin{array}{l}\text { Level of } \\
\text { evidence }\end{array}$ & Definition \\
\hline 19 & $\begin{array}{l}\text { Systematic reviews (with homogeneity) of } \\
\text { randomized controlled trials }\end{array}$ \\
\hline $1 \mathrm{~b}$ & $\begin{array}{l}\text { Individual randomized controlled trials (with } \\
\text { narrow confidence interval) }\end{array}$ \\
\hline IC & All or none randomized controlled trials \\
\hline $2 \mathrm{a}$ & $\begin{array}{l}\text { Systematic reviews (with homogeneity) of cohort } \\
\text { studies }\end{array}$ \\
\hline $2 \mathrm{~b}$ & $\begin{array}{l}\text { Individual cohort studies or low-quality } \\
\text { randomized controlled trials }\end{array}$ \\
\hline $2 c$ & Outcomes research or ecological studies \\
\hline 3a & $\begin{array}{l}\text { Systematic review (with homogeneity) of case- } \\
\text { control studies }\end{array}$ \\
\hline $3 \mathrm{~b}$ & Individual case-control studies \\
\hline 4 & $\begin{array}{l}\text { Case-series (and poor-quality cohort and case- } \\
\text { control studies) }\end{array}$ \\
\hline 5 & $\begin{array}{l}\text { Expert opinion without explicit critical } \\
\text { appraisal or based on physiology, fundamental } \\
\text { research, or first principles }\end{array}$ \\
\hline
\end{tabular}

ommendations. For categories 1 and 2, levels of evidence (LEs) have been described according to the general principles of evidence-based medicine (Table 1) [1]. Grades of recommendation (GR) were taken into account to determine (1) quality of evidence; (2) balance between desirable and undesirable effects; (3) values and preferences; and (4) use of resources. GR were defined as strong recommendations or weak recommendations [2].

\section{MANAGEMENT OF METASTATIC HOR- MONE-SENSITIVE PROSTATE CANCER}

\section{Key question 1-1: What is the significance of andro- gen deprivation therapy?}

\begin{tabular}{lcc}
\hline Recommendation & LE & GR \\
\hline $\begin{array}{l}\text { The primary treatment for metastatic prostate } \\
\text { cancer is androgen deprivation therapy }\end{array}$ & SR \\
(surgical castration [bilateral orchiectomy] or & & \\
medical castration based on LHRH agonist), & & \\
which prevents the clinical progression of the & & \\
disease and relieves the symptoms. & & \\
\hline $\begin{array}{l}\text { LHRH antagonist can also be considered as } \\
\text { the primary treatment for metastatic prostate }\end{array}$ & WR \\
cancer. & & \\
\end{tabular}

The growth of mHSPC relies on the androgen receptor (AR) and the androgen signaling pathway; hence, androgen deprivation therapy (ADT) is used to treat patients with mHSPC [3-6]. In patients with metastatic prostate cancer, ADT typically involves surgical castration (bilateral orchiectomy) or medical castration with luteinizing hormone-releasing hormone (LHRH) agonists and antagonists. There is no high-level evidence supporting the use of LHRH agonists or orchiectomy [7], and LHRH agonists and antagonists provide similar efficacy [8]. Medical castration is often preferred due to cosmetic and psychological reasons, and due to the fact 
that surgical castration is irreversible. LHRH agonists can cause testosterone flare in some patients, worsening early clinical symptoms. In patients receiving LHRH agonists, serum testosterone reach castration levels in approximately 1 to 4 weeks after treatment initiation; thus, treatment with antiandrogens for at least 7 days before administrating LHRH agonists may be required to prevent the exacerbation of clinical symptoms. In contrast to LHRH agonists, LHRH antagonists do not cause a testosterone flare and reach castration levels within 3 days of injection [9].

\section{Key question 1-2: What is the clinical significance of docetaxel in $\mathrm{mHSPC}$ ?}

\begin{tabular}{|c|c|c|}
\hline Recommendation & LE & GR \\
\hline $\begin{array}{l}\text { Docetaxel should be considered in patients } \\
\text { with high volume disease who are fit for } \\
\text { chemotherapy. }\end{array}$ & 1a & SR \\
\hline $\begin{array}{l}\text { Docetaxel can be considered in patients } \\
\text { with low volume disease who are fit for } \\
\text { chemotherapy. }\end{array}$ & 1a & WR \\
\hline
\end{tabular}

The GETUG-AFU15 [10], CHAARTED [11], and STAMPEDE [12] studies evaluated the clinical significance of docetaxel in mHSPC patients. GETUG-AFU15 was a 1:1 randomized phase 3 study that compared the ADT plus docetaxel with $\mathrm{ADT}$ alone, and the primary endpoint was overall survival (OS). Docetaxel $\left(75 \mathrm{mg} / \mathrm{m}^{2}\right.$, every 3 weeks) was administered for up to nine cycles [10]. The results revealed that ADT plus docetaxel provided longer progression-free survival (PFS) than ADT alone (median, 23.5 months vs. 15.4 months; hazard ratio [HR], 0.75; 95\% confidence interval [CI], 0.59 to $0.94 ; p=0.015$ ), but did not improve OS (median, 58.9 months vs. 54.2 months; HR, 1.01; 95\% CI, 0.75 to $1.36 ; p=0.955$ ).

The CHAARTED, a 1:1 randomized phase 3 study of 790 patients with mHSPC, compared the ADT plus docetaxel with ADT alone, and the primary endpoint was OS [11]. Unlike GETUG-AFU15, the results of CHAARTED revealed that $\mathrm{ADT}$ plus docetaxel provided a longer OS than ADT alone (median, 57.6 months vs. 44.0 months; HR, o.61; $p<0.001$ ). Additionally, ADT plus docetaxel improved most secondary endpoints, including the time to clinical progression and the time to CRPC. Subgroup analysis revealed that the clinical benefit of combination therapy was more apparent in patients with high-volume disease (HVD; defined as the presence of visceral metastases or $\geq 4$ bone lesions with $\geq 1$ beyond the vertebral bodies and pelvis) than in the overall study population; in this subgroup, ADT plus docetaxel provided a significantly longer OS than ADT alone (median OS, 49.2 months vs. 32.2 months; HR, o.6o; 95\% CI, 0.45 to 0.81 ; $p$ < 0.001 ). Severe docetaxel-related adverse events (grade 3 or higher) were observed in $16.7 \%$ of patients. Allergic reaction, fatigue, diarrhea, stomatitis, and peripheral neuropathy were the most common side effects, and only one treatment-related death was reported. A recent long-term follow-up study of the CHAARTED cohort confirmed the clinical benefits of docetaxel in patients with $\mathrm{mHSPC}$ [13].

STAMPEDE was a randomized, multi-arm, controlled trial investigating the clinical efficacy of different firstline treatments in men undergoing long-term hormone therapy as the standard of care (SOC) for newly diagnosed locally advanced, metastatic, or recurring prostate cancer. The survival outcomes in patients receiving first-line docetaxel, zoledronic acid, or both in combination with hormone therapy were reported in 2016 [12]. The median OS was 71 months for SOC-only, 81 months for SOC + docetaxel (HR, 0.78; 95\% CI, 0.66 to $0.93 ; p=0.006)$, and 76 months for SOC + zoledronic acid + docetaxel (HR, o.82; 95\% CI, 0.69 to $0.97 ; p=0.022$ ). Long-term follow-up of the STAMPEDE cohort demonstrated that ADT plus docetaxel significantly prolonged OS, PFS, and failure-free survival (FFS), regardless of the disease volume (high or low volume disease) [14].

However, the volume of metastasis and other baseline characteristics differed significantly among the patients of these studies. Furthermore, the rate of docetaxel-related deaths was lower in the CHAARTED study than in the GETUG-AFU 15 study ( $1 \%$ vs. $7 \%$ ). The frequency of exposure to other treatments (abiraterone, enzalutamide, and cabazitaxel) also differed across these studies. Additionally, most (about $80 \%$ ) of ADT alone group in GETUG-AFU15 study received docetaxel after disease progression, which indicating that GETUG-AFU15 trial was more a trial of early versus delayed docetaxel [15]. Two meta-analysis studies confirmed that the combination of docetaxel with ADT improved OS in patients with mHSPC $[16,17]$. Therefore, docetaxel administration should be considered in patients who are suitable for chemotherapy, especially in patients with HVD. 


\section{Key question 1-3: What is the clinical significance of the androgen receptor-targeted agents?}

\begin{tabular}{lcc}
\hline Recommendation & LE & GR \\
\hline $\begin{array}{l}\text { Abiraterone/prednisone, apalutamide or } \\
\text { enzalutamide (alphabetical) should be }\end{array}$ & Ib & SR \\
considered as standard primary therapy in & & \\
mHSPC. & & \\
\hline
\end{tabular}

The combination of docetaxel with ADT is widely accepted as the SOC for mHSPC $[11,12]$. However, because many prostate cancer patients are elderly and have multiple underlying comorbidities, and are not fit for docetaxel, other treatment option is needed in these patients. To address the need for further treatment options in MHSPC, studies have investigated the clinical usefulness of androgen receptor-targeted agents (ARTA) in mHSPC patients. Abiraterone acetate is a selective inhibitor of androgen biosynthesis that potently blocks cytochrome $\mathrm{P}_{450} \mathrm{c} 17$ (CYP17), a critical enzyme in testosterone synthesis, thereby blocking androgen synthesis by the adrenal glands and testes and within the prostate tumor [18]. Enzalutamide [19] and apalutamide [20] are selective antagonists of the androgen receptor (AR) which inhibits AR translocation to the cell nucleus, recruitment of AR cofactors and AR binding to DNA.

LATITUDE was a multinational, 1:1 randomized, double-blind, placebo-controlled, phase III trial evaluating the efficacy of abiraterone/prednisone combined with ADT in men with newly diagnosed high-risk mHSPC. The primary endpoints were OS and radiographic progression-free survival (rPFS). High-risk disease was defined as tumors with at least two of the following characteristics: (1) Gleason score of 8 or higher; (2) at least three bone lesions; and (3) presence of measurable visceral metastasis [21]. Patients in the abiraterone group exhibited better OS (median OS, not reached [NR] vs. 34.7 months) and rPFS (median rPFS, 33.0 months vs. 14.8 months) than those in the placebo group (OS [HR, 0.62; 95\% CI, 0.51 to $0.76 ; p<0.001$ ], rPFS [HR, $0.47 ; 95 \% \mathrm{CI}, 0.39$ to 0.55 ; $p<0.001])$. The superiority of abiraterone over placebo was also obvious for all secondary endpoints (time to pain progression, time to prostate-specific antigen [PSA] progression, time to next symptomatic skeletal event, time to chemotherapy, time to subsequent prostate cancer therapy). The long-term clinical benefits of abi- raterone combined with $\mathrm{ADT}$ in patients with mHSPC have recently been reported [22].

A similar survival benefit of abiraterone/prednisone in mHSPC was demonstrated in STAMPEDE [23]. This study was a 1:1 random assignment study of 1917 HSPC patients comparing the combination of $\mathrm{ADT}$ and abiraterone/prednisone and $\mathrm{ADT}$ alone, about $50 \%$ of which were metastatic disease. Abiraterone significantly improved OS (HR, 0.63; 95\% CI, 0.52 to 0.76 ; $p<0.001$ ) and FFS (HR, $0.29 ; 95 \%$ CI, 0.25 to $0.34 ; p<0.001)$. The benefit of abiraterone for OS was demonstrated in preplanned subgroup analysis of 1002 patients with metastatic disease at entry (HR, 0.61; 95\% CI, 0.49 to 0.75). A recent post hoc analysis of the STAMPEDE study was performed to evaluate the heterogeneity of effect between LATITUDE high- and low-risk "metastatic" prostate cancer patients receiving ADT with abiraterone/prednisone in the STAMPEDE study [24]. The combination of ADT with abiraterone/prednisone provided a significantly better OS than ADT alone. Heterogeneity of effect was not seen between low- and high-risk groups for OS or FFS.

The multinational, 1:1 randomized, open-label, phase III trial ENZAMET compared the efficacy of early enzalutamide and standard nonsteroidal antiandrogens (SOC group: bicalutamide, nilutamide, or flutamide) in 1,125 patients with mHSPC [25]; the primary study endpoint was OS. At the first interim analysis, there were 102 deaths in the enzalutamide group and 143 deaths in the SOC group (HR, 0.67; 95\% CI, 0.52 to $0.86 ; p=$ 0.002 ). Enzalutamide group exhibited superior OS than SOC group (3-year OS rates, $80 \%$ vs. $72 \%$ ). Additionally, enzalutamide significantly improved key secondary endpoints, including PSA-PFS (HR, o.39; $p<0.001)$ and clinical PFS (HR, $0.40 ; p<0.001)$.

The multinational, 1:1 randomized, double-blind, placebo-controlled, phase III trial ARCHES compared the efficacy of enzalutamide combined with ADT to that of ADT plus placebo in 1,150 patients with $\mathrm{MHSPC}$; the primary study endpoint was rPFS [26]. Compared with placebo plus ADT, enzalutamide plus ADT significantly reduced the risk of radiographic progression by $61 \%$ (HR, 0.39; 95\% CI, 0.30 to $0.50 ; p<0.001$ ). Median rPFS was NR in the enzalutamide group (95\% CI, NR to NR) versus 19.0 months (95\% CI, 16.6 to 22.2) with placebo. The superiority of enzalutamide combination treatment 
was also apparent for key secondary endpoints, including the time to PSA progression, the time to initiation of new antineoplastic therapy, PSA undetectable rate, and objective response rate.

TITAN, a multinational, 1:1 randomized, double-blind, placebo-controlled, phase III trial, evaluated the effects of combination therapy with apalutamide and $\mathrm{ADT}$ on rPFS and OS in 1,052 patients with mHSPC [27]. The 2-year rPFS rates were $68.2 \%$ in the apalutamide group and $47.5 \%$ in the placebo group (HR, 0.48; 95\% CI, 0.39 to $0.60 ; p<0.001)$. The 2 -year OS rates were $82.4 \%$ in the apalutamide group and $73.5 \%$ in the placebo (OS: HR, $0.67 ; 95 \% \mathrm{CI}, 0.51$ to $0.89 ; p=0.005$ ).

The ENZAMET, ARCHES, and TITAN studies permitted early docetaxel or included patients who had been treated with early docetaxel. In the ENZAMET study, the early administration of docetaxel $\left(75 \mathrm{mg} / \mathrm{m}^{2}\right.$, every 3 weeks, up to six cycles) was permitted as a stratification factor before randomization. Subgroup analysis revealed a smaller OS benefit of enzalutamide in the early docetaxel group (HR, 0.90; 95\% CI, 0.62 to 1.31). In contrast, the OS benefit of enzalutamide was apparent in patients without planned early docetaxel use (HR, 0.53; 95\% CI, 0.37 to 0.75). In the TITAN and ARCHES studies, before randomization, patients were stratified based on previous early docetaxel use. rPFS improvement after treatment with enzalutamide or apalutamide was observed in patients with or without previous docetaxel use. However, subgroup analysis of the TITAN cohort failed to confirm the benefit of apalutamide on OS (HR, 1.27; $95 \%$ CI, 0.52 to 3.09 ) in patients who previously received early docetaxel. The effects of enzalutamide on OS based on previous docetaxel exposure were not reported in the ARCHES study. Currently, the clinical efficacy of ARTA in patients with mHSPC previously or concomitantly treated with docetaxel is unclear.

\section{Key question 1-4: What should be considered in determining the treatment of $\mathrm{mHSPC}$ ?}

\begin{tabular}{|c|c|c|}
\hline Recommendation & $\mathrm{LE}$ & GR \\
\hline $\begin{array}{l}\text { Immediate ADT should be performed to } \\
\text { prevent disease progression, symptoms and } \\
\text { complications. }\end{array}$ & $\mathrm{lb}$ & SR \\
\hline $\begin{array}{l}\text { Deferred ADT may be considered in patients } \\
\text { with well-informed asymptomatic patients } \\
\text { if the risk of treatment related side effects is } \\
\text { greater than treatment benefits. }\end{array}$ & $2 b$ & WR \\
\hline $\begin{array}{l}\text { Abiraterone/prednisone, apalutamide, } \\
\text { docetaxel, or enzalutamide (alphabetical) } \\
\text { should be considered as standard primary } \\
\text { therapy and clinician's judgement is } \\
\text { important in treatment choice. }\end{array}$ & $\mathrm{lb}$ & SR \\
\hline
\end{tabular}

Determination to start systemic treatment for $\mathrm{mHSPC}$ ADT should be implemented immediately for symptomatic patients. However, the benefit of asymptomatic patients from ADT remains controversial due to thelack of evidence from well-designed studies which were conducted in the era of clinical use of PSA and included heterogeneous patients group [28-30]. However, considering the poor prognosis of metastatic disease, immediate ADT should be considered in metastatic patients, even if they are asymptomatic. Deferred ADT may be considered for asymptomatic patients if the risk of treatment-related side effects is greater than the treatment benefits.

Clinical consideration for determining treatment strategy Careful consideration is required when deciding a treatment strategy. To date, no large-cohort studies have compared the clinical efficacy of cytotoxic chemotherapy (docetaxel) and ARTA in patients with MHSPC. Table 2 summarizes the main characteristics of different agents and results of key phase III clinical trials in patients with mHSPC. 
Table 2. Results of four major phase III clinical studies on metastatic hormone-sensitive prostate cancer

\begin{tabular}{|c|c|c|c|c|}
\hline & $\begin{array}{l}\text { LATITUDE } \\
(\mathrm{n}=1,199)[21]\end{array}$ & $\begin{array}{c}\text { TITAN } \\
(\mathrm{n}=1,052)[27]\end{array}$ & $\begin{array}{l}\text { CHAARTED } \\
(\mathrm{n}=790)[11]\end{array}$ & $\begin{array}{l}\text { ENZAMET } \\
(\mathrm{n}=1,125)[25]\end{array}$ \\
\hline Agent & Abiraterone & Apalutamide & Docetaxel & Enzalutamide \\
\hline Control & Placebo & Placebo & Placebo & $\begin{array}{l}\text { Nonsteroidal } \\
\text { antiandrogen }\end{array}$ \\
\hline $\begin{array}{l}\text { Primary endpoint, HR } \\
\text { (95\% CI) }\end{array}$ & $\begin{array}{l}\text { OS: } 0.62(0.51-0.76) \\
\text { rPFS: } 0.47(0.39-0.55)\end{array}$ & $\begin{array}{l}\text { OS: } 0.67(0.51-0.89) \\
\text { rPFS: } 0.48(0.39-0.60)\end{array}$ & OS: $0.72(0.59-0.89)$ & OS: $0.67(0.52-0.86)$ \\
\hline Duration, mo & $\begin{array}{l}\text { Median OS: NR vs. } 34.7 \\
\text { Median rPFS: } 33.0 \text { vs. } \\
14.8\end{array}$ & $\begin{array}{l}\text { Median OS: NR vs. NR } \\
\text { Median rPFS: NR vs. } \\
\mathbf{2 2 . 1}\end{array}$ & Median OS: 57.6 vs. 47.2 & Median OS: NR vs. NR \\
\hline Prior ADT, mo & Up to 3 & Up to 6 & Up to 4 & Up to 3 \\
\hline $\begin{array}{l}\text { Prior/concurrent } \\
\text { docetaxel }\end{array}$ & Exclusion & Prior docetaxel (10\%) & Exclusion & $\begin{array}{l}\text { Concurrent docetaxel } \\
(45 \%)\end{array}$ \\
\hline De novo $\mathrm{M} 1, \%$ & 100 & 80 & 73 & 60 \\
\hline Visceral metastases, \% & 5 & 12 & 15 & 12 \\
\hline AE of interest ${ }^{\mathrm{a}}$ & $\begin{array}{l}\text { Elevated liver enzymes, } \\
\text { electrolyte imbalance, } \\
\text { hypertension }\end{array}$ & $\begin{array}{l}\text { Rash, seizures, } \\
\text { hypothyroidism }\end{array}$ & $\begin{array}{l}\text { Neutropenia, } \\
\text { peripheral neuropathy }\end{array}$ & Seizures, falls \\
\hline Corticosteroid & Yes & No & No & No \\
\hline Population & 100\% high risk ${ }^{b}$ & All & $65 \%$ High volumes $^{c}$ & All \\
\hline
\end{tabular}

HR, hazard ratio; CI, confidence interval; OS, overall survival; rPFS, radiographic progression-free survival; NR, not reached; ADT, androgen deprivation therapy; AE, adverse event.

${ }^{\mathrm{a}} \mathrm{AE}$ of interest: These are AEs of special interest, not most common AEs.

${ }^{\mathrm{b}}$ High risk: At least 2 of 3 high risk criteria (Gleason score of $\geq 8$, presence of $\geq 3$ lesions on bone scan, presence of measurable visceral lesion).

${ }^{\mathrm{c}}$ High volumes: Visceral metastases (extra-nodal) and/or bone metastases (at least 4 or more bone lesions, one of which must be outside of the vertebral column or pelvis).

\section{MANAGEMENT OF METASTATIC CASTRA- TION-RESISTANT PROSTATE CANCER}

\section{Key question 2-1: What should be considered with diagnosis of castration resistance?}

\begin{tabular}{|c|c|c|}
\hline Recommendation & LE & GR \\
\hline $\begin{array}{l}\text { Castration resistant prostate cancer is defined } \\
\text { as following. }\end{array}$ & 5 & $\mathrm{SR}$ \\
\hline $\begin{array}{l}\text { Serum testosterone }<50 \mathrm{ng} / \mathrm{dL} \text { or } 1.7 \mathrm{nmol} / \mathrm{L} \\
\text { plus either: }\end{array}$ & & \\
\hline $\begin{array}{l}\text { 1. Three consecutive rises in PSA at least } 1 \\
\text { week apart over the nadir, and a PSA > } 2 \\
\mathrm{ng} / \mathrm{mL}\end{array}$ & & \\
\hline $\begin{array}{l}\text { 2. Appearance of } 2 \text { or more new lesions in } \\
\text { bone scan or progressive disease using } \\
\text { RECIST version } 1.1\end{array}$ & & \\
\hline
\end{tabular}

CRPC is defined as disease progression despite effective suppression of serum testosterone. The castration level of serum testosterone is defined as less than $50 \mathrm{ng} / \mathrm{dL}$ or $1.7 \mathrm{nmol} / \mathrm{L}$. CRPC is defined as castration level of serum testosterone plus one of the followings: (1) three consecutive rises (over the nadir) in PSA levels at least 1 week apart, and a PSA > $2 \mathrm{ng} / \mathrm{mL}$ (biochemical progression); (2) development of two or more new lesions in bones or progressive disease according to Response Evaluation Criteria in Solid Tumors (RECIST) version 1.1 [4,5,31-33] criteria (radiographic progression). In addition, EAU guideline mentions PSA rise resulting two 50\% increases over the nadir for biochemical progression. If bone lesions are the only indicator of disease progression, at least two new lesions should appear in the bone scan for a CRPC diagnosis; ambiguous results should be con- 
firmed by other imaging modalities. For patients who develop CRPC, ADT with an LHRH agonist or antagonist should be continued to maintain castration level of serum testosterone. For patients treated with combined androgen blockade, antiandrogens could be discontinued to exclude an antiandrogen withdrawal response. Antiandrogen withdrawal response is characterized by PSA reduction, occasionally accompanied by a radiographic response, and typically occurs 4 to 6 weeks after the discontinuation of first-generation antiandrogen therapy [34]. However, if the disease progression is obvious or suspected of rapid progression, this approach is not appropriate and should be changed to subsequent treatment.

\section{Key question 2-2: What is the clinical significance of androgen receptor-targeted agents?}

\begin{tabular}{lcc}
\hline Recommendation & LE & GR \\
\hline $\begin{array}{l}\text { Abiraterone/prednisone and enzalutamide } \\
\text { (alphabetical) are important treatment }\end{array}$ & Ib & SR \\
options not only for patients who have & & \\
progressed after docetaxel, but also for & & \\
patients who have not previously received \\
docetaxel.
\end{tabular}

Two phase III trials were conducted to evaluate the clinical efficacy of abiraterone and enzalutamide in patients with metastatic CRPC (mCRPC) who had not been previously treated with chemotherapy. The multinational, 1:1 randomized, double-blind, placebo-controlled, phase III trial COU-AA-302 compared the effects of abiraterone plus prednisone to those of placebo plus prednisone in 1,088 chemotherapy-naïve patients with progressive mCRPC (but no visceral metastasis) who had asymptomatic or mildly symptomatic disease; the primary endpoints were rPFS and OS [35]. No symptoms or mild symptoms were defined as follows: (1) Eastern Cooperative Oncology Group (ECOG) performance status grade of $\mathrm{O}-1$; or (2) Brief Pain Inventory-Short Form (BPI-SF) scores from o-3. The median rPFS was 16.5 months in the abiraterone group and 8.3 months in the placebo group (HR, 0.53; 95\% CI, 0.45 to $0.62 ; p<$ 0.001). Median OS was NR in the abiraterone group and was 27.2 months in the placebo group (HR, 0.75; 95\% CI, 0.61 to $0.93 ; p=0.01)$. Notably, abiraterone consistently improved rPFS and OS in all prespecified subgroups. A preplanned interim analysis of COU-AA-302 evaluating patient-reported pain and functional status revealed that abiraterone treatment delayed the progression of patient-reported pain and deterioration of the quality of life [36].

The multinational, 1:1 randomized, double-blind, placebo-controlled, phase III trial PREVAIL compared the clinical efficacy of enzalutamide to that of placebo in 1717 chemotherapy-naïve patients with progressive mCRPC and who had asymptomatic or mildly symptomatic disease; the primary endpoints of the study were rPFS and OS [37]. In contrast to COU-AA-302, PREVAIL included patients with visceral metastasis. No symptoms or mild symptoms were defined with the same criteria as the COU-AA-302 study (ECOG o-1, BPI-SF score o-3). The median rPFS (NR vs. 3.9 months) and median OS (32.4 months vs. 30.2 months) were longer in enzalutamide-treated patients than in patients treated with placebo (rPFS [HR, o.19; 95\% CI, o.15 to 0.23; $p<0.001$ ], OS [HR, $0.71 ; 95 \% \mathrm{CI}$, 0.60 to $0.84 ; p<0.001]$ ). The treatment effect of enzalutamide on rPFS and OS was consistent across all prespecified subgroups.

Two phase III trials were conducted to evaluate the clinical efficacy of abiraterone and enzalutamide in MCRPC patients who had previously undergone chemotherapy. The multinational, 2:1 randomized, double-blind, placebo-controlled, phase III trial COU-AA-301 evaluated the effects of abiraterone plus prednisone in 1,195 patients with progressive mCRPC who had previously been treated with chemotherapy [38]. The primary endpoint was OS. The median OS was 14.8 months in the abiraterone plus prednisone group and 10.9 months in the prednisone alone group ( $\mathrm{HR}, 0.74 ; 95 \% \mathrm{CI} 0.64$ to o.86; $p<0.001$ ). Importantly, abiraterone consistently improved OS in all subgroups. Additionally, abiraterone improved all secondary endpoints analyzed, including the confirmed PSA response rate, the objective response rate in patients with measurable disease at baseline, the time to PSA progression, and rPFS. The long-term clinical benefits of abiraterone were recently confirmed in a longer follow-up study [39].

AFFIRM was a multinational, 2:1 randomized, double-blind, placebo-controlled, phase III trial evaluating the effect of enzalutamide in 1,199 patients with progressive mCRPC who had previously undergone chemotherapy [40]. The primary endpoint was OS. The median 
OS was 18.4 months in the enzalutamide group and 13.6 months in the placebo group (HR, 0.63; 95\% CI, 0.53 to $0.75 ; p<0.001)$. The OS benefit of enzalutamide was consistent across all subgroups. The superiority of enzalutamide over placebo was consistent across all secondary endpoints, including PSA response rate, soft tissue response rate, health-related quality of life, time to PSA progression, rPFS, and time to the first skeletal-related event.

The adverse events of abiraterone and enzalutamide have also been investigated. In COU-AA-301 trial, adverse events associated with $\mathrm{CYP}_{17}$ inhibition and elevated mineralocorticoid levels (fluid retention, edema, hypokalemia, and hypertension), cardiac disorders, and liver function abnormalities were more common in the abiraterone acetate group than in the placebo group ( $55 \%$ vs. $43 \%, p<0.001$ ). Meanwhile, a higher incidence of any grade fatigue, diarrhea, hot flashes, musculoskeletal pain, and headache was observed in the enzalutamide group than in the placebo group. Notably, the AFFIRM study revealed that five of 800 patients (0.6\%) receiving enzalutamide experienced seizures; some of these patients had predisposing conditions or received concomitant treatments. Thus, caution should be used with patients with a history of seizures, patients receiving concomitant medication that may lower the seizure threshold, and those who have other predisposing factors, including brain injury, stroke, brain metastases, or alcoholism. Additionally, an increased risk of falls was observed in older patients treated with enzalutamide [41].

Treatment with abiraterone plus prednisone, and enzalutamide should be considered for chemotherapy-naïve patients and those with progressive disease after treatment with docetaxel. To date, no studies have directly compared the safety and efficacy of enzalutamide and abiraterone plus prednisone. The differences in their mechanisms of action may result in differences in their toxicity profiles, and clinicians should carefully consider the patient's underlying diseases and clinical conditions.

\section{Key question 2-3: What is the clinical significance of cytotoxic chemotherapy?}

\begin{tabular}{lcc}
\hline Recommendation & LE & GR \\
\hline $\begin{array}{l}\text { Docetaxel with prednisone is a standard } \\
\text { therapy for first line cytotoxic chemotherapy }\end{array}$ & 1b & SR \\
in patients with mCRPC & & \\
$\begin{array}{l}\text { Cabazitaxel with prednisone is one of the } \\
\text { standard therapies in patients with mCRPC } \\
\text { who have previously received docetaxel. }\end{array}$ & 1b & SR \\
\hline
\end{tabular}

The multinational, 1:1:1 randomized, non-blinded, phase III trial $\mathrm{TAX}_{327}$ compared the effects of docetaxel (given either every 3 weeks or weekly) plus prednisone with that of mitoxantrone plus prednisone in 1,006 patients with $\mathrm{mCRPC}$. Patients received $5 \mathrm{mg}$ of prednisone twice daily and were randomly assigned to receive $75 \mathrm{mg} / \mathrm{m}^{2}$ of docetaxel every 3 weeks, $30 \mathrm{mg} / \mathrm{m}^{2}$ of docetaxel weekly for 5 of every 6 weeks, or $12 \mathrm{mg} / \mathrm{m}^{2}$ of mitoxantrone every 3 weeks. OS was the primary endpoint of the study [42]. Patients in the 3-week docetaxel group (median OS, 18.9 months) but not those in the 1-week docetaxel group (median OS, 17.4 months) had a longer OS than patients in the mitoxantrone group (median OS, 16.5 months). There were 166 (50\%) deaths (HR, 0.76; 95\% CI, 0.62 to $0.94 ; p=0.009)$ in the 3 -week docetaxel group, 190 (57\%) deaths (HR, $0.91 ; 95 \% \mathrm{CI}, 0.75$ to $1.11 ; p=00.36)$ in the weekly docetaxel group, and $201(60 \%)$ deaths in the mitoxantrone group. Hair loss (62\%), fatigue (53\%), diarrhea (32\%), and grade 3 or 4 neutropenia (32\%) were observed in patients treated with docetaxel every 3 weeks. A longer follow-up study of the TAX 327 cohort confirmed the superiority of docetaxel plus prednisone (every 3 weeks) over mitoxantrone plus prednisone in terms of mCRPC patient survival [43].

Although the TAX327 study demonstrated the clinical efficacy of $75 \mathrm{mg} / \mathrm{m}^{2}$ docetaxel every 3 weeks, concerns remain regarding the relatively high toxicity rates. PROSTY was a multinational, 1:1 randomized, non-blinded, phase III trial comparing the effects of 75 $\mathrm{mg} / \mathrm{m}^{2}$ of 3-weekly docetaxel plus prednisone with those of $50 \mathrm{mg} / \mathrm{m}^{2}$ 2-weekly docetaxel plus prednisone in 361 patients with $\mathrm{MCRPC}$; the primary endpoint of the study was time to treatment failure (TTTF) [44]. The median TTTF and OS were longer in the 2-weekly group than in the 3-weekly group (median TT'TF, 5.6 months vs. 4.9 months; HR, 1.3; 95\% CI, 1.1 to $1.6 ; p=0.014)(\mathrm{OS}$, 
19.5 months vs. 17.0 months; HR, 1.5; $95 \% \mathrm{CI}, 1.1$ to $1.8 ; p$ $=0.021$ ). Severe adverse events were more frequent in the 3-weekly docetaxel group than in the 2-weekly docetaxel group (neutropenia [HR, 2.3, 95\% CI, 1.2 to $4.2 ; p=0.007$ ], leucopenia [HR, 2.8; 95\% CI, 1.0 to 7.6; $p=0.046$ ], infections with neutropenia [HR, 4.1; 95\% CI, 1.1 to $15.4 ; p=$ 0.034]). The findings of this study suggest that 2-weekly docetaxel could be a safe option for patients who are not suitable for a 3-weekly regimen. The COU-AA-302 [35] and PREVAIL [37] studies confirmed the clinical benefit of abiraterone plus prednisone and enzalutamide in docetaxel-naïve patients. However, these studies were conducted in asymptomatic or minimally symptomatic patients. Therefore, docetaxel remains a important treatment option for patients requiring symptom management and those with visceral metastasis.

Cabazitaxel is an important treatment option for mCRPC patients previously treated with docetaxel. TROPIC was a multinational, 1:1 randomized, open-label, phase III trial evaluating the effects of cabazitaxel plus prednisone and mitoxantrone plus prednisone in 755 patients with $\mathrm{mCRPC}$ who had progressed during or after treatment with a docetaxel-containing regimen. The primary endpoint of the study was OS [45]. The median OS was 15.1 months in patients receiving cabazitaxel plus prednisone and 12.7 months in patients receiving mitoxantrone plus prednisone (HR, 0.70; $95 \%$ CI, 0.59 to $0.83 ; p<0.001$ ). Subgroup analyses of OS consistently favored cabazitaxel group. Additionally, cabazitaxel plus prednisone improved most secondary endpoints, including PFS (median PFS, 2.8 months vs. 1.4 months; HR, $0.74 ; p<0.0001$ ), tumor response rate, PSA response, and PSA-PFS. However, severe adverse events (grade 3 or higher) were more frequent in the cabazitaxel group (57.4\%) than in the mitoxantrone group (39.4\%). The most common side effects of cabazitaxel were hematological grade 3 or 4 adverse events, including neutropenia, leukopenia, and anemia. The most common non-hematological grade 3 or 4 adverse event was diarrhea. Peripheral neuropathy (any grade) was observed in $14 \%$ of patients in the cabazitaxel group and in $3 \%$ of patients in the mitoxantrone group. Treatment discontinuation due to severe toxicity was required in $18 \%$ of patients in the cabazitaxel group and in $4 \%$ of patients in the mitoxantrone group. Dose modifications (delay or reduction) and prophylactic treatment with granulocyte colony-stimulating factor (G-CSF) in high-risk patients are potential strategies to mitigate the risk of toxicity.

The PROSELICA study assessed whether $20 \mathrm{mg} / \mathrm{m}^{2}$ cabazitaxel (C20) was noninferior, in terms of OS, to $25 \mathrm{mg} / \mathrm{m}^{2}$ cabazitaxel (C25) [46]. The median OS was 13.4 months in the $\mathrm{C} 20$ group and 14.5 months in the $\mathrm{C} 25$ group (HR, 1.024), suggesting that the clinical efficacy of $\mathrm{C} 20$ and $\mathrm{C}_{25}$ are similar in terms of OS. PSA response rates and time to PSA progression were superior in the $\mathrm{C} 25$ group than in the $\mathrm{C} 2 \mathrm{O}$ group. The incidence of most severe (grade 3 or higher) adverse effects (e.g., fatigue, hematuria, neutropenia, and febrile neutropenia) was lower in patients receiving $\mathrm{C} 20$ (39.7\%) than those receiving $\mathrm{C} 25$ (54.5\%). The results of this study suggest that cabazitaxel provides a similar clinical benefit at 20 and $25 \mathrm{mg} / \mathrm{m}^{2}$, while the incidence of manageable grade 3 or higher adverse events is relatively low, particularly in patients receiving $20 \mathrm{mg} / \mathrm{m}^{2}$ cabazitaxel. Thus, $20 \mathrm{mg} / \mathrm{m}^{2}$ of cabazitaxel could be a feasible treatment option when a standard dose of cabazitaxel is unlikely to be tolerated.

FIRSTANA, a multinational, 1:1:1 randomized, open-label, phase 3 trial designed to demonstrate whether cabazitaxel $25 \mathrm{mg} / \mathrm{m}^{2}(\mathrm{C} 25)$ or $20 \mathrm{mg} / \mathrm{m}^{2}$ (C20) was superior to docetaxel $75 \mathrm{mg} / \mathrm{m}^{2}$ (D75) [47]. The median OS was 24.5 months in the C20 group, 25.2 months in the $\mathrm{C} 25$ group, and 24.3 months in the D75 group. No statistically significant differences were observed between the three treatment groups in terms of OS, PFS, PSA response, and pain response; therefore, the study failed to demonstrate the superiority of cabazitaxel over docetaxel as a first-line treatment. The usefulness of cabazitaxel administration before docetaxel treatment remains to be demonstrated.

With the treatment options rapidly expanding, many studies have investigated the most effective treatment sequences. The multicenter, 1:1 randomized, open-label, phase III trial CARD compared cabazitaxel with either abiraterone or enzalutamide (ARTA) in 255 patients with mCRPC who had previously received docetaxel and who had disease progression within 12 months while they had been receiving alternative ARTA. The primary endpoint of the study was imaging-based progression-free survival (iPFS) [48]. The median iPFS was 8.0 months in the cabazitaxel group and 3.7 months in the ARTA group (HR, 0.54; 95\% CI. 0.40 to 0.73 ; $p<0.001$ ). The clinical benefit of cabazitaxel to prolong iPFS was consistent 
in all prespecified subgroups. The median OS was 13.6 months in the cabazitaxel group and 11.0 months in the ARTA group (HR, 0.64; 95\% CI, 0.46 to $089 ; p=0.008$ ). The incidence of adverse events (any grade) was similar in the cabazitaxel group (38.9\%) and in the ARTA group (38.7\%). In this study, prophylactic treatment with G-CSF was mandatory during each cycle of cabazitaxel, and severe febrile neutropenia (grade 3 or higher) was observed in $3.2 \%$ of patients. Therefore, cabazitaxel should be considered in patients previously treated with docetaxel and ARTA, especially in patients whose tumors rapidly progressed during ARTA treatment. Primary G-CSF prophylaxis should also be considered in these patients.

\section{Key question 2-4: What is the clinical significance of radium-223 treatment in patients with bone metas- tasis?

\begin{tabular}{lcc}
\hline Recommendation & LE & GR \\
\hline Radium-223 can be considered in CRPC & lb & WR \\
patients with symptomatic bone metastases & & \\
and no known visceral metastasis. & & \\
\hline
\end{tabular}

Radium-223 dichloride (radium-223), an alpha emitter, selectively targets bone metastases with alpha particles. The multicenter, 2:1 randomized, double-blind, placebo-controlled, phase III trial ALSYMPCA evaluated the efficacy and safety of radium-223 in 921 CRPC patients with bone metastasis who had received, were not eligible to receive, or declined docetaxel. Patients received six intravenous injections of radium-223 $(50 \mathrm{kBq} / \mathrm{kg})$ or matching placebo; one injection was administered every 4 weeks. The primary endpoint of the study was OS [49]. The median OS was 14.0 months in the radium-223 group and 11.2 months in the placebo group. Compared with placebo, radium-223 treatment was associated with a $30 \%$ reduction in the risk of death (HR, 0.70; 95\% CI, 0.58 to $0.83 ; p<0.001)$. The effect of radium-223 on OS was consistent across all subgroups. All main secondary efficacy end points including first symptomatic skeletal event provided support for the benefit of radium-223 over placebo. The frequency of adverse events did not differ between the radium-223 and placebo groups.

The multicenter, 1:1 randomized, double-blind, placebo-controlled, phase III trial ERA223 assessed the efficacy and safety of radium-223 and abiraterone plus prednisone in chemotherapy-naïve patients with as- ymptomatic or mildly symptomatic mCRPC (bone metastases). Patients received up to six injections of radium-223 $(55 \mathrm{kBq} / \mathrm{kg})$ or placebo every 4 weeks. The primary endpoint of the study was symptomatic skeletal event-free survival [50]. Median symptomatic skeletal event-free survival was 22.3 months in the radium-223 group and 26.0 months in the placebo group (HR, 1.122; $95 \%$ CI, 0.917 to $1.374 ; p=0.263)$. The incidence of fracture was higher in the radium-223 group (29\%) than in the placebo group (11\%). Osteoporotic fractures were the most common fractures in the radium-223 group ( $49 \%$ in radium-223 vs. $17 \%$ in placebo). These findings suggest that radium-223 may increase the risk of osteoporotic fractures. The effects of radium-223 combined with enzalutamide and bone-protecting agents, such as denosumab and zoledronic acid, are currently under clinical investigation. Based on currently available data, we do not recommend the combination of radium-223 with abiraterone plus prednisone, docetaxel, or enzalutamide.

\section{Key question 2-5: What is the status of precision medicine in prostate cancer?}

\begin{tabular}{lcc}
\hline Recommendation & LE & GR \\
\hline $\begin{array}{l}\text { In order for precision medicine to be applied } \\
\text { to clinical practice, the evidence of accurate }\end{array}$ & WR \\
diagnosis and effective treatment for specific & & \\
genetic alteration are required. Recently, & & \\
many trials targeting BRCA and others are & & \\
ongoing. & & \\
\hline
\end{tabular}

Precision cancer treatment based on genomic tumor profiling at the point-of-care is transforming the treatment of several cancers, including advanced prostate cancer [51]. Recently, several studies on DNA damage repair (DDR) genes have been conducted in prostate cancer. Specifically, alterations in DNA repair genes were identified in nearly $20 \%$ of all primary prostate cancer samples. Among these, BRCA1 and BRCA2 alterations were found in $1 \%$ and $3 \%$ of samples, respectively [52]. BRCA1/2 alterations have been associated with aggressive tumor phenotypes and poor prognosis [53]. A recent study identified genomic defects in DNA repair genes in $20 \%$ to $30 \%$ of advanced CRPC samples; BRCA2 was identified as a promising target in mCRPC, being mutated in $10 \%$ of mCRPC patients [54]. 
The multicenter, open-label, single-group, two-stage, phase II study TOPARP-A evaluated the efficacy of olaparib as salvage therapy in 50 patients with mCRPC. The response rate was the primary endpoint of the study [55]. Of the 50 patients, 16 patients (33\%) had mutations in DDR genes, including BRCA2; 14 of these 16 biomarker-positive patients (88\%) responded to olaparib, but only $6 \%$ of biomarker-negative patients exhibited a response. OS and rPFS were significantly longer in the biomarker-positive group than in the biomarker-negative group (median OS: 13.8 months vs. 7.5 months, $p=$ 0.05; median rPFS: 9.8 months vs. 2.7 months, $p<0.001$ ).

The multicenter, openlabel, investigator-initiated, randomized, phase II trial TOPARPB validated the antitumor activity of olaparib in 711 patients with mCRPC harboring DDR gene alterations. Patients with DDR gene alterations were randomly assigned (1:1) into two groups, balancing for circulating tumor cell (CTC) count at screening. Patients were administered with 400 or 300 mg olaparib twice daily, given continuously in 4-week cycles until disease progression or unacceptable toxicity. Composite response was the primary endpoint of the study, and was defined as any of the following: radiological objective response by RECIST 1.1; a decrease of 50\% or more in PSA levels from baseline; or conversion of CTC count from $\geq 5$ cells per $7.5 \mathrm{~mL}$ blood at baseline to $<5$ cells [56]. In total, 161 (22.6\%) patients had DDR gene alterations, 98 of whom were randomly assigned and treated. Confirmed composite response was observed in $54.3 \%$ of patients in the $400 \mathrm{mg}$ group and in $39.1 \%$ of patients in the $300 \mathrm{mg}$ group. Composite response rates according to DDR gene alterations were reported as $83.3 \%$ in BRCA1 $/ 2,36.8 \%$ in ATM, $25.0 \%$ in CDK12, and $57.1 \%$ in PALB2.

PROfound was a 2:1 randomized open-label phase III trial evaluating the efficacy and safety of olaparib (compared with enzalutamide or abiraterone) in patients with mCRPC with genetic alterations in any of 15 predefined homologous recombination repair genes; in all patients, the disease had progressed on prior enzalutamide or abiraterone treatment [57]. Cohort A included patients with alterations in BRCA1, BRCA2, or ATM, and cohort $\mathrm{B}$ included patients with alterations in any of the following genes: BRIP1, BARD1, CDK12, CHEK1, CHEK2, FANCL, PALB2, PPP2R2A, RAD51B, RAD ${ }_{51}$, $\mathrm{RAD}_{51 \mathrm{D}}$, or RAD54L. Primary endpoint was $\mathrm{rPFS}$ in co- hort A. The median rPFS was 7.4 months in the olaparib group and 3.6 months in the control group (HR, 0.34; 95\% CI, 0.25 to $0.47 ; p<0.001$ ). The objective response rates were $33.3 \%$ in the olaparib group and $2.3 \%$ in the control group. Therefore, PARP inhibition is a promising option for the treatment of CRPC patients harboring DDR gene alterations.

Recently, immune checkpoint inhibitors have shown promising antitumor effects in various cancers. Several ongoing studies are evaluating the efficacy of immunotherapy in prostate cancer. The randomized double-blind phase III trial CA184-095 investigated the efficacy and safety of ipilimumab as the first-line treatment of patients with asymptomatic or minimally symptomatic $\mathrm{mCRPC}$ without visceral metastases. OS was the primary endpoint of the study [58]. Median OS was 28.7 months in the ipilimumab group and 29.7 months in the placebo group. Although ipilimumab did not improve OS, the median PFS was longer in the ipilimumab group than in the placebo group (5.6 months vs. 3.8 months; HR, 0.67; 95\% CI, 0.55 to 0.81 ).

KEYNOTE-o28 was a multicenter, open-label, phase Ib trial evaluating the efficacy and safety of pembrolizumab in patients with PD-L1-positive advanced solid tumors, including 23 patients with prostate adenocarcinoma [59]. It revealed that the objective response rate in PD-L1-positive patients was 17.4\%. KEYNOTE-199, a multicohort open-label phase II study, investigated the effects of pembrolizumab in 258 patients with mCRPC treated with docetaxel and one or more ARTA [6o]. The objective response rate was $5 \%$ in the PD-L1-positive group and $3 \%$ in the PD-L1-negative group. Numerous ongoing studies are investigating the efficacy and safety of immune checkpoint inhibitors in prostate cancer.

\section{Key question 2-6: What are the trends in the treat- ment of non-metastatic CRPC?}

\begin{tabular}{lll}
\hline Recommendation & LE & GR \\
\hline $\begin{array}{l}\text { The ADT should also be maintained in } \\
\text { patients with non-metastatic CRPC, and }\end{array}$ & lb & WR \\
ARTA (apalutamide, darolutamide and & & \\
enzalutamide, [alphabetically]) can be & & \\
considered in patients with PSADT $\leq 10$ & & \\
months, and careful observation can be taken & & \\
in patients with PSADT > 10 months. & &
\end{tabular}


Non-metastatic castration-resistant prostate cancer (MoCRPC) is characterized by PSA progression despite primary $\mathrm{ADT}$ and the absence of apparent metastatic lesions in conventional imaging [61]. The findings of several studies suggest that patients with shorter PSA doubling time (PSADT) are at greater risk for developing metastasis $[62,63]$. In patients with PSADT of 10 months or less, treatment with apalutamide, darolutamide, and enzalutamide combined with ADT can be considered.

The international, 2:1 randomized, placebo-controlled, phase III trial SPARTAN evaluated the effect of apalutamide on metastasis-free survival (MFS) in 1,207 men with MoCRPC and PSADT of $\leq 10$ months. The primary endpoint was MFS, defined as the time from randomization to the first detection of distant metastasis or death from any cause (whichever occurred first) [64]. The median MFS was 40.5 months in the apalutamide group and 16.2 months in the placebo group (HR, $0.28 ; 95 \% \mathrm{CI}, 0.23$ to $0.35 ; p<0.001$ ). The effect of apalutamide to prolong MFS was consistent across all prespecified subgroups. The following adverse events occurred more frequently in the apalutamide group than in the placebo group: fatigue (30.4\% vs. $21.1 \%)$, rash (23.8\% vs. $5.5 \%)$, falls ( $15.6 \%$ vs. $9.0 \%)$, fracture ( $11.7 \%$ vs. $6.5 \%)$, and hypothyroidism (8.1\% vs. $2.0 \%)$.

PROSPER, an international, 2:1 randomized, placebo-controlled, phase III trial, evaluated the effect of enzalutamide on MFS in 1,401 men with MoCRPC and $\mathrm{PSADT} \leq 10$ months. The primary endpoint of the study was MFS [65]. The median MFS was 36.6 months in the enzalutamide group and 14.7 months in the placebo group (HR, 0.29; 95\% CI, 0.24 to 0.35 ; $p<0.001$ ). The clinical benefit of enzalutamide was consistent across all prespecified subgroups. The most common adverse event in patients receiving enzalutamide was fatigue. Adverse events of special interest that occurred more frequently (by $\geq 2$ percentage points) in the enzalutamide group than the placebo group, were hypertension ( $12 \%$ vs. $5 \%$ ), major adverse cardiovascular events (5\% vs. $3 \%)$, and mental impairment disorders (5\% vs. $2 \%$ ).

The international, 2:1 randomized, placebo-controlled, phase III trial ARAMIS investigated the effect of darolutamide on MFS in 1,509 patients with MoCRPC and PSADT of $\leq 10$ months. The primary endpoint of the study was MFS [66]. The median MFS was 40.4 months in the darolutamide group and 18.4 months in the pla- cebo group (HR, 0.41; 95\% CI, 0.34 to 0.50 ; $p<0.001$ ). All prespecified subgroups benefited from darolutamide treatment. The incidence of adverse events was generally similar in the darolutamide and placebo groups. Key adverse events that are known to be associated with ARTAs including fracture, falls, seizures, and weight loss were not different between darolutamide and placebo.

Meanwhile, for patients with PSADT of $>10$ months, patients can be closely monitored for disease progression and development of clinical symptoms [63].

\section{Key question 2-7: What should be considered in determining treatment in $\mathrm{MCRPC}$ ?}

\begin{tabular}{lcc}
\hline Recommendation & LE & GR \\
\hline The decision of treatment should be & 1a & SR \\
determined comprehensively considering & & \\
their previous treatment history, performance & & \\
status, presence of visceral metastasis, and & & \\
presence of symptoms. & & \\
\hline
\end{tabular}

In patients without previous docetaxel use

The primary treatments for mCRPC patients without previous docetaxel use are docetaxel and abiraterone plus prednisone or enzalutamide. To date, no large-cohort studies have compared the efficacies of docetaxel, abiraterone, or enzalutamide in patients who did not previously receive docetaxel; therefore, clinical decisions should be based on a comprehensive evaluation of the patient's symptoms, presence of visceral metastasis, and performance status.

Docetaxel is an important primary treatment for patients with symptomatic mCRPC with or without visceral metastasis. Docetaxel can be used in patients with suspected rapid progression, even in the absence of symptoms or visceral metastasis. However, no guidelines have been developed regarding docetaxel treatment duration in patients with docetaxel-sensitive tumors. In the $\mathrm{TAX}_{327}$ study [42], patients received up to 10 cycles of docetaxel. A recent study suggested that the continuation of docetaxel chemotherapy for over six cycles may provide a survival benefit [67]. However, clinicians should also consider the potential toxicity and quality of life impairment associated with prolonged docetaxel use.

Enzalutamide and abiraterone plus prednisone are also important primary treatments, significantly im- 
proving the survival of patients with asymptomatic or minimally symptomatic $\mathrm{mCRPC}$, according to the findings of the COU-AA-3O2 and PREVAIL studies. Considering that most mCRPC patients are elderly and often have poor performance status, enzalutamide and abiraterone plus prednisone may be considered as alternatives to docetaxel in symptomatic patients. After progression of abiraterone/prednisone or enzalutamide, there is limited study of subsequent therapy. A post hoc analysis of the COU-AA-302 cohort evaluated the clinical benefit of docetaxel in patients with progressive disease after treatment with abiraterone plus prednisone [68]. Among 100 patients who received docetaxel as first subsequent therapy, $40 \%$ had an unconfirmed PSA decline (by $\geq 50 \%$ ), and $27 \%$ had a confirmed PSA decline (by $\geq$ $50 \%)$. The median duration of docetaxel treatment was 4.2 months. Docetaxel was the most common first subsequent therapy in that study, but $43 \%$ of elderly patients and $17 \%$ of young patients received no subsequent therapy for $\mathrm{mCRPC}$.

A phase II study assessed the best sequence of abiraterone/prednisone and enzalutamide treatment, as well as their efficacy as second-line treatment [69]. Patients were randomly assigned (1:1) to receive either abiraterone plus prednisone until PSA progression followed by crossover to enzalutamide (group A); patients in group B received the opposite sequence. The primary endpoint was time to second PSA progression, defined as the time from first-line therapy initiation to confirmed PSA progression on second-line therapy or death. The time to second PSA progression was longer in group A than in group B (19.3 months vs. 15.2 months); nevertheless, OS did not differ between the two groups. In the patient population that crossed over to second-line therapy, the time to PSA progression on second-line therapy was 3.5 months in group A and 1.7 months in group B. Docetaxel may be more appropriate option as subsequent therapy after 1st line abiraterone/ prednisone or enzalutamide in patients who are fit for chemotherapy.

In patients with previous docetaxel use

Abiraterone plus prednisone, enzalutamide and cabazitax are of clinical benefit in patients with previous docetaxel use. In determining subsequent treatment after docetaxel, the risks and benefits of the treatment, and
Table 3. Summary of systemic treatment in mCRPC

In patients with asymptomatic or minimally symptomatic mCRPC and with no previous docetaxel treatment

Offer abiraterone or enzalutamide in patients who are suitable for these agents

Offer docetaxel in patients who are suitable for docetaxel ${ }^{\mathrm{a}}$

In patients with symptoms or presence of visceral metastasis and with no previous docetaxel treatment Offer docetaxel in patients who are suitable for docetaxel

Offer abiraterone or enzalutamide in patients who are suitable for these agents ${ }^{\mathrm{b}}$

Consider radium-223

In patients with bone metastases

Offer denosumab or zoledronic acid in MCRPC to prevent skeletal-related events

mCRPC, metastatic castration-resistant prostate cancer.

${ }^{a}$ For patients who shows signs of rapid progression or visceral metastases.

${ }^{b}$ For patients who cannot receive or refused docetaxel.

${ }^{\mathrm{c}}$ For patients with symptomatic bone metastases and without visceral metastases, who are not eligible for other treatments.

the patient's quality of life should be taken into careful consideration. Meanwhile, docetaxel re-challenge may be considered in selected patients with $\mathrm{mCRPC}$. Previous study investigated the efficacy and tolerance of subsequent treatments (chemotherapy and ARTAs) in patients treated upfront with docetaxel for mHSPC using data from patients included in the GETUG-AFU 15 trial. For docetaxel used in first- or second line, a PSA decline $\geq 50 \%$ was observed in $14 \%$ who had received upfront ADT plus docetaxel [70]. The results of other studies suggest that docetaxel re-challenge may be used as salvage therapy in patients with longer re-challenge interval and previous response to docetaxel [71-73]. Therefore, docetaxel re-challenge as salvage therapy may be an option for selected patients.

Table 3 summarizes the currently available systemic treatments for mCRPC. 


\section{CLINICAL CONSIDERATIONS FOR THE TREAT- MENT OF METASTATIC PROSTATE CANCER}

\section{Key question 3-1: What is an appropriate efficacy assessment and monitoring of systemic treatment in metastatic prostate cancer?}

Recommendation

Serum PSA, radiologic imaging (CT/MRI), bone scan, and clinical symptoms of the patient should be monitored, and the interval and method should be decided according to the individual patient's disease status.

Radiologic imaging play an important role in the management of patients with advanced solid cancer. RECIST is commonly mostly used to evaluate treatment responses [32]; however, RECIST criteria are not ideal for prostate cancer because bone metastasis is common, and measurable lesions are only in 40\% of mCRPC cases and in $15 \%$ of mHSPC cases [74]. Thus, RECIST working group suggested that disease and therapy-specific modifications to RECIST should be considered in prostate cancer [33]. Patient monitoring and response evaluation in cases of prostate cancer should be conducted comprehensively with evaluations of serum PSA levels, radiologic imaging, bone scans, and clinical symptoms.

Efficacy monitoring in patients with $\mathrm{mHSPC}$

Although the majority of patients with mHSPC initially respond to ADT, most patients progress to $\mathrm{MCRPC}$ within approximately 1 year. Therefore, it is important to monitor the disease progression to $\mathrm{MCRPC}$ and determine subsequent therapy accordingly. The effective assessment and monitoring methods of pivotal clinical trials in mHSPC vary slightly from study to study.

The LATITUDE study assessed the efficacy of abiraterone in patients with $\mathrm{mHSPC}$ using sequential radiographic imaging every 4 months, starting at week 16; imaging modalities included computed tomography (CT), magnetic resonance imaging (MRI), and bone scans. PSA levels were measured at baseline, monthly in the first year, and then every 2 months until the end of treatment [21]. The ENZAMET study monitored the efficacy of enzalutamide in patients with mHSPC using CT and bone scan performed at baseline and when disease progression was suspected. PSA levels were measured at baseline, at week 4 , and then every 12 weeks until the end of treatment [25]. The CHAARTED trial investigated the efficacy of docetaxel in patients with mHSPC using PSA levels measured at each scheduled visit. CT and bone scans were performed at baseline and at the time of documented castration resistance or as clinically indicated [11]. According to the National Comprehensive Cancer Network (NCCN) guidelines, a bone scan is recommended every 6 to 12 months, and soft tissue imaging (CT or MRI) is recommended regularly, but no exact interval is not mentioned [4].

Considering the above, it is not appropriate to apply the same assessment guidelines to all patients. For example, frequent disease status assessment with imaging is not appropriate for patients with low metastatic burden, a small number of bone lesions, no visceral metastasis, or slow PSA progression. In contrast, patients with high metastatic volumes and rapid PSA progression require frequent monitoring by serum PSA measurements, radiologic imaging (CT/MRI), bone scans, and clinical symptom evaluation; the interval and method of monitoring should be decided according to the individual patient's disease status. In particular, patients with a high disease burden and those with expected rapid progression should be monitored carefully and frequently.

Efficacy assessment in patients with $\mathrm{mCRPC}$

The RECIST working group suggested that disease-specific adaptations are needed in prostate cancer because imaging-based response evaluation alone is not sufficient given the unique characteristics of prostate, and introduced Prostate Cancer Working Group (PCWG) criteria in CRPC [33]. Currently, several international guidelines $[4,5]$ also discourage disease evaluation using imaging methods alone.

We propose that in $\mathrm{mCRPC}$, disease progression is defined as when it meet at least two of the following three criteria; PSA progression, radiographic progression, and clinical deterioration. For PSA progression, the criteria suggested by PCWG2 are most commonly used. For patients with PSA levels lower than the baseline, PSA progression should be defined as an increase by $\geq 25 \%$ or an absolute increase of $2 \mathrm{ng} / \mathrm{mL}$ or more from the nadir; the increase in PSA levels should be confirmed by 3 or more weeks later. For patients whose PSA didn't decline from baseline PSA progression is defined as a $25 \%$ or greater increase and an absolute increase of $2 \mathrm{ng} / \mathrm{mL}$ 
or more from the baseline after 12 weeks. Radiographic progression is defined as the appearance of two or more new lesions in the bone metastases or progressive disease in soft tissues, lymph nodes, or visceral metastasis according to RECIST criteria. Therefore, disease progression in mCRPC should be confirmed by a comprehensive evaluation of PSA levels, imaging findings, and clinical symptoms. In general, we recommend that clinical symptoms, PSA levels, and other blood tests should be evaluated every 3 to 4 weeks, and CT, MRI, and bone scan should be performed every 12 weeks. The interval and method may be adjusted based on the individual patient's disease status.

\section{Key question 3-2: What is a proper medical manage- ment for bone health?}

\begin{tabular}{l} 
Recommendation \\
\hline Denosumab or zoledronic acid should be given to mCRPC \\
patients with bone metastases for preventing skeletal \\
related events \\
Prevention and management of osteoporosis induced by \\
ADT are required.
\end{tabular}

Medical management for bone health in patients with metastatic prostate cancer differs depending on disease status. In mCRPC patients with bone metastases who are at high risk of skeletal complications, the main goal of treatment is to prevent skeletal complications and improve prognosis. In mHSPC patients who are expected to receive long-term $\mathrm{ADT}$, the main purpose of the treatment is to prevent and manage osteoporosis induced by ADT.

\section{Management of bone metastases in MCRPC}

Bone metastasis occurs in more than $90 \%$ of CRPC patients and is one of the main causes of death, disability, poor quality of life, and high treatment costs. A randomized, double-blinded, placebo-controlled trial evaluated the effects of zoledronic acid in MCRPC patients with bone metastases [75]. Patients were randomly assigned to receive intravenous zoledronic acid (4 mg) or placebo every 3 weeks for 15 months [75]. Skeletal complications were less frequent in the zoledronic acid group than in the placebo group (33.2\% vs. $44.2 \%, p=0.021$ ). The median time to the first skeletal-related event was 321 days in the placebo and was NR in the zoledronic acid group
( $p=0.011$ ). OS did not differ between the two groups. Long-term treatment with zoledronic acid (4 mg) provided sustained clinical benefits for mCRPC patients with bone metastases [76]. Other bisphosphonate drugs, including pamidronate and clodronate, are not recommended for these patients because they do not show significant clinical benefit [77,78].

Denosumab is a humanized monoclonal antibody that inhibits receptor activator of nuclear factor kappa-B ligand (RANKL) activation and is currently approved for the prevention of skeletal-related events in patients with bone metastases from solid tumors. The study NCTo0321620 was an international, double-blinded, 1:1 randomized, phase III trial comparing the efficacy of denosumab to that of zoledronic acid in 1901 CRPC patients with bone metastases; the primary endpoint of the study was time to the first skeletal-related event [79]. Patients were assigned to receive $120 \mathrm{mg}$ subcutaneous denosumab plus intravenous placebo or $4 \mathrm{mg}$ intravenous zoledronic acid plus subcutaneous placebo every 4 weeks. Compared with zoledronic acid, denosumab significantly delayed the time to the first skeletal-related event by $18 \%$ (median, 20.7 months vs. 17.1 months; HR, 0.82; 95\% CI, 0.71 to $0.95 ; p=0.002$ ). OS did not differ significantly between the treatment groups. The clinical benefit of zoledronic acid and denosumab to prevent skeletal-related events has only been demonstrated in CRPC. In mHSPC, zoledronic acid did not provide a clinical benefit in terms of skeletal-related events $[80,81]$, and no clinical trials have assessed the effects of denosumab.

Patients receiving denosumab or zoledronic acid should be closely monitored for potential toxicities, including osteonecrosis of the jaw and hypocalcemia. Osteonecrosis of the jaw is a relatively uncommon but potentially serious side effect. Dental health evaluation should be conducted before treatment with denosumab or zoledronic acid because the risk of osteonecrosis of the jaw is increased by previous dental trauma, infections, or dental surgery $[82,83]$. Hypocalcemia is a major concern in patients treated with denosumab or zoledronic acid. Serum calcium levels should be measured before treatment and should be monitored throughout the treatment. Daily oral calcium and vitamin D supplement are recommended in all patients except those with hypercalcemia [84]. 
Management of ADT-induced osteoporosis

ADT significantly impairs bone health, decreasing bone mass density and increasing the risk of fractures [85]. $\mathrm{ADT}$ is known to increase the risk of fractures from $21 \%$ to $54 \%$, and long-term ADT is strongly associated with a high risk of fractures [86,87]. NCCN guideline for prostate cancer [4] recommends that supplement of calcium (1,000 to $1,200 \mathrm{mg}$, daily) and vitamin $\mathrm{D}_{3}$ (400 to 1,000 $\mathrm{IU}$, daily) for patients undergoing $\mathrm{ADT}$ and additional treatments in patients over the age of 50 with $\mathrm{T}$ score between -1.0 and -2.5 at the femoral neck, total hip, or lumbar spine by the dual energy X-ray absorptiometry (DEXA), and the risk of a 10-year hip fracture is $3 \%$ or greater or the risk of a major osteoporosis-related fracture is $20 \%$ or greater calculated by the Fracture Risk Assessment Tool (FRAX) algorithm.

In prostate cancer patients receiving $\mathrm{ADT}$, bisphosphonates increase bone mineral density, a surrogate marker for bone fractures [88,89]. A randomized phase III study revealed that denosumab treatment in patients receiving ADT for non-metastatic prostate cancer was associated with increased bone mineral density at all sites and a reduction in the incidence of new vertebral fractures [90]. The Korean Society for Bone and Mineral Research recommends the administration of alendronate (oral, $70 \mathrm{mg}$, weekly), zoledronic acid (intravenous, $5 \mathrm{mg}$, annually), and denosumab (subcutaneous, 60 mg, every 6 months) in patients who are at high risk of ADT-induced fractures.

\section{Key question 3-3: What is the role of radiotherapy in bone metastasis?}

Recommendation

Radiotherapy provides relief of pain induced by bone metastasis

Bone metastasis is usually associated with overstimulation of osteoclasts and osteoblasts. Pain is common among patients with bone metastasis due to tumor-induced disruption of the balance between osteoclasts and osteoblasts, tumor-induced nerve damage, production of factors causing nerve irritation, and tumor-induced muscle spasms. Radiotherapy relieves pain by reducing the activity of osteoclasts, inflammatory cells, and chemical mediators, in addition to reducing the size of the tumor [91-93].
Several randomized trials have demonstrated that radiotherapy can relieve pain. The Radiation Therapy Oncology Group trial 97-14 was a prospective phase III trial investigating whether radiotherapy (8 Gy delivered in a single treatment fraction) provided pain and narcotic relief similar to that of standard treatment (30 Gy delivered in ten treatment fractions over 2 weeks) [94]. The results revealed that both regimens were equivalent in terms of pain and narcotic relief within 3 months and were well tolerated with few adverse effects. The non-blinded, randomized, controlled trial NCTooo80912 confirmed that treatment with $8 \mathrm{~Gy}$ in a single fraction was non-inferior and less toxic than 20 Gy delivered in multiple fractions [95].

Patients who have been responding to radiotherapy can also experience pain due to disease progression. Several studies which investigated the delivery of reirradiation to the same site of painful bone metastases have demonstrated that pain response rates was up to $50 \%$ [96]. Another meta-analysis reported that pain response after reirradiation was achieved in $58 \%$ of patients [97]. Therefore, re-irradiation of radiation-refractory bone pain can be used in selected patients.

\section{Key question 3-4: What are the adverse effects of ADT?}

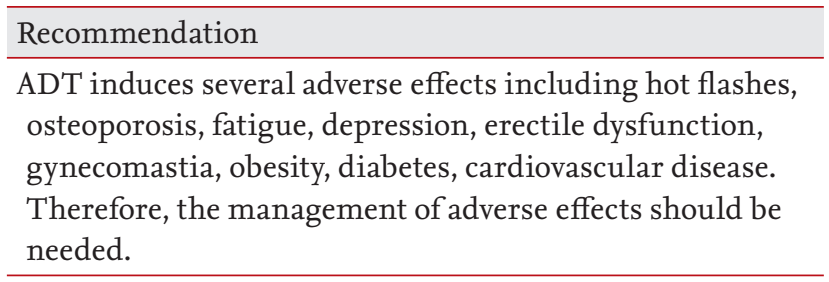

Hot flashes are one of the most common symptomatic side effects associated with ADT. Up to $80 \%$ of patients receiving LHRH agonists experience hot flashes [98]. Hot flashes mostly occur about 3 months after ADT initiation, and long-term hot flashes significantly affect quality of life [99]. Although treatment with estrogen receptor modulators or low dose estrogen (e.g., $0.5 \mathrm{mg} /$ day) can relieve symptoms, this increases the risk of cardiovascular complications [100].

Sexual dysfunction is also very common, occurring in up to $90 \%$ of patients receiving ADT. Efforts to mitigate sexual dysfunction using phosphodiesterase 5 inhibitors and vacuum-assisted devices have shown limited 
efficacy [99].

Gynecomastia is observed in approximately $25 \%$ of patients receiving ADT, significantly affecting psychological wellbeing and quality of life, as well as inducing breast pain. For patients with severe gynecomastia, treatment with tamoxifen and irradiation may be considered. Tamoxifen is more useful as primary prevention, and irradiation can improve gynecomastia that has already occurred [101,102].

The bone-related adverse effects of ADT are discussed above in key question 3-2.

Cardiovascular disease and diabetes are the most common causes of death induced by adverse events of ADT, and it is even known to exceed prostate cancer itself as a cause for death among prostate cancer patients [103-105]. Many studies have evaluated the relationship between ADT and cardiovascular diseases. One observational population-based study found that the use of LHRH agonists was associated with an increased risk of diabetes, coronary heart disease, myocardial infarction, and sudden cardiac death. A large meta-analysis published in 2015 reported that $\mathrm{ADT}$ increased the risks of myocardial infarction, non-fatal cardiovascular diseases, and stroke [106]. However, several other studies have found no relationship between ADT and cardiovascular diseases [28,105,107-113]. Some studies have found an association between ADT and death due to cardiovascular disease only in patients with known risk factors or a history of cardiovascular disease $[108,114,115]$. The American Heart Association (AHA), the American Cancer Society, and the American Urologic Association have published guidelines regarding the management of risk factors [116]. AHA suggests the Awareness \& Aspirin, Blood pressure, Cholesterol \& Cigarette, Diet \& Diabetes, and Exercise (ABCDE) method for prostate cancer survivors [117].

Neurocognitive impairments have also been reported in patients receiving ADT [118]. A large-cohort study reported a significant relationship between $\mathrm{ADT}$ and risk of dementia [119]. The results regarding the relationship between ADT and cognitive function are conflicting [120-124]. Nevertheless, the possibility of cognitive impairment should be taken into account before starting $\mathrm{ADT}$, especially in patients with underlying neurocognitive disorders.

\section{Key question 3-5: What is the diagnosis and treat- ment of small cell/neuroendocrine prostate cancer?}

\begin{tabular}{l}
\hline Recommendation \\
\hline Small cell/neuroendocrine prostate cancer should \\
be considered when patients showed rapid disease \\
progression with high metastatic burden, high prevalence \\
osteolytic bone metastases, despite of low serum PSA \\
level. Biopsy should be considered when small cell/ \\
neuroendocrine prostate cancer is suspected.
\end{tabular}

Primary small cell/neuroendocrine prostate cancer is an very rare yet aggressive disease. Treatment-related small cell/neuroendocrine prostate cancer ( $t$-NEPC) is more common than primary small cell/neuroendocrine prostate cancer. Long-term ADT is associated with an increased risk of small cell/neuroendocrine prostate cancer [125,126]. Small cell/neuroendocrine prostate cancer has a unique clinical presentation, including a short-term or no response to $\mathrm{ADT}$, rapid progression, high prevalence of lytic bone lesions, presence of visceral metastases, a markedly enlarged prostate, serum neuroendocrine markers (chromogranin A, synaptophysin, neuron-specific enolase) and low PSA level relative to disease burden [127,128]. A prospective study of metastatic tumor biopsies found an overall t-NEPC incidence of 17\% [129]. Notably, t-NEPC was associated with inferior $\mathrm{OS}$ in patients treated with abiraterone or enzalutamide for mCRPC (HR, 2.02; 95\% CI, 1.07 to 3.82). Interestingly, genomic alterations in DDR genes were nearly mutually exclusive with t-NEPC differentiation. When small cell/ neuroendocrine prostate cancer is suspected, a biopsy of accessible sites should be considered to identify patients with NEPC pathological features and require disease management [127,130].

Currently, no standard treatment has been established for small cell/neuroendocrine prostate cancer. Patients diagnosed with small cell/neuroendocrine prostate cancer are often treated with platinum-based cytotoxic chemotherapy (e.g., cisplatin plus etoposide, carboplatin plus etoposide, or docetaxel plus carboplatin), which are also often used in patients with small-cell lung cancer [131]. A recent phase II study compared the clinical efficacy of cabazitaxel in combination with carboplatin to that of cabazitaxel monotherapy in mCRPC patients with histological evidence of prostate adenocarcinoma, small-cell prostate carcinoma, or both [132]. This study 
conducted molecular profiling of tumor biopsy which showed virulent, atypical clinical features, defined them as aggressive variant prostate cancer molecular signature (AVPC-MS) composed of combined defects in at least two of the three tumor suppressors TP53, RB1, and PTEN, and then performed sub-group analysis. Patients with AVPC-MS who received cabazitaxel plus carboplatin had a significantly longer PFS than those treated with cabazitaxel alone (median PFS, 7.5 months vs. 1.7 months, $p=0.017$ ). Additionally, OS was longer in patients treated with cabazitaxel plus carboplatin than those treated with cabazitaxel monotherapy (median OS, 20.2 months vs. 8.5 months, $p=0.0002$ ). These results suggest that platinum-based chemotherapy may be a feasible treatment option for patients with small cell/ neuroendocrine prostate cancer.

\section{CONCLUSIONS}

The treatment landscape of metastatic prostate cancer is changing rapidly, and numerous trials are ongoing to identify novel therapies for patients with metastatic prostate cancer. It is necessary to verify the results of clinical studies. Given that many patients with prostate cancer are elderly or have multiple underlying conditions, clinicians should carefully consider the clinical efficacy and safety of systemic treatments. Based on emerging evidence from clinical studies, we will continue to update the Korean guidelines for the management of metastatic prostate cancer.

\section{Conflict of interest}

No potential conflict of interest relevant to this article was reported.

This guideline is made for general information and educational purpose only, do not provide specific legal or reimbursement advice.

\section{Acknowledgments}

This study was supported by a grant from the National R\&D Program for Cancer Control, Ministry of Health and Welfare, Republic of Korea (1720150). The present guideline was prepared by the Korean Society of Medical Oncology (KSMO)/ Korean Cancer Study Group (KCSG). We would like to express our sincere thanks to all the committee members of this guideline development. And we would like to express gratitude to Professor Jae Lyun Lee, who is the chairman of the genitourinary/gynecological cancer committee of KCSG. Professor Jae Lyun Lee's contributions span from the publication of the first version of this guideline, to the present 2 nd edition.

\section{REFERENCES}

1. The Centre for Evidence-Based Medicine. Levels of evidence (March 2009) [Internet]. Oxford (UK): Centre for Evidence-Based Medicine, 2009 [cited 2020 Dec 8]. Available from: http://www.cebm.net/index.aspx?o=1025.

2. Guyatt GH, Oxman AD, Vist GE, et al. GRADE: an emerging consensus on rating quality of evidence and strength of recommendations. BMJ 2008;336:924-926.

3. Morris MJ, Rumble RB, Basch E, et al. Optimizing anticancer therapy in metastatic non-castrateprostate cancer: American Society of Clinical Oncology clinical practice guideline. J Clin Oncol 2018;36:1521-1539.

4. National Comprehensive Cancer Network. Prostate cancer (Version 2.2019) [Internet]. Plymouth Meeting (PA): NCCN, 2019 [cited 2020 Dec 8]. Available from: https:// www.nccn.org/professionals/physician_gls/pdf/prostate. pdf.

5. Cornfford P, Bellmunt J, Bolla M, et al. EAU-ESTRO-SIOG guidelines on prostate cancer. Part II: treatment of relapsing, metastatic, and castration-resistant prostate cancer. Eur Urol 2017;71:630-642.

6. Parker C, Gillessen S, Heidenreich A, Horwich A; ESMO Guidelines Committee. Cancer of the prostate: ESMO clinical practice guidelines for diagnosis, treatment and follow-up. Ann Oncol 2015;26 Suppl 5:v69-v77.

7. Samson DJ, Seidenfeld J, Schmitt B, et al. Systematic review and meta-analysis of monotherapy compared with combined androgen blockade for patients with advanced prostate carcinoma. Cancer 2002;95:361-376.

8. Trachtenberg J, Gittleman M, Steidle C, et al. A phase 3, multicenter, open label, randomized study of abarelix versus leuprolide plus daily antiandrogen in men with prostate cancer. J Urol 2002;167:1670-1674.

9. Klotz L, Boccon-Gibod L, Shore ND, et al. The efficacy and safety of degarelix: a 12-month, comparative, randomized, open-label, parallel-group phase III study in 
patients with prostate cancer. BJU Int 2008;102:1531-1538.

10. Gravis G, Fizazi K, Joly F, et al. Androgen-deprivation therapy alone or with docetaxel in non-castrate metastatic prostate cancer (GETUG-AFU 15): a randomised, open-label, phase 3 trial. Lancet Oncol 2013;14:149-158.

11. Sweeney CJ, Chen YH, Carducci M, et al. Chemohormonal therapy in metastatic hormone-sensitive prostate cancer. N Engl J Med 2015;373:737-746.

12. James ND, Sydes MR, Clarke NW, et al. Addition of docetaxel, zoledronic acid, or both to first-line long-term hormone therapy in prostate cancer (STAMPEDE): survival results from an adaptive, multiarm, multistage, platform randomised controlled trial. Lancet 2016;387:11631177.

13. Kyriakopoulos CE, Chen YH, Carducci MA, et al. Chemohormonal therapy in metastatic hormone-sensitive prostate cancer: long-term survival analysis of the randomized phase III E3805 CHAARTED trial. J Clin Oncol 2018;36:1080-1087.

14. Clarke NW, Ali A, Ingleby FC, et al. Addition of docetaxel to hormonal therapy in low- and high-burden metastatic hormone sensitive prostate cancer: long-term survival results from the STAMPEDE trial. Ann Oncol 2019;30:19922003.

15. Gravis G, Boher JM, Joly F, et al. Androgen deprivation therapy (ADT) plus docetaxel versus ADT alone in metastatic non castrate prostate cancer: impact of metastatic burden and long-term survival analysis of the randomized phase 3 GETUG-AFU15 trial. Eur Urol 2016;70:256262.

16. Tucci M, Bertaglia V, Vignani F, et al. Addition of docetaxel to androgen deprivation therapy for patients with hormone-sensitive metastatic prostate cancer: a systematic review and meta-analysis. Eur Urol 2016;69:563573.

17. Vale CL, Burdett S, Rydzewska LHM, et al. Addition of docetaxel or bisphosphonates to standard of care in men with localised or metastatic, hormone-sensitive prostate cancer: a systematic review and meta-analyses of aggregate data. Lancet Oncol 2016;17:243-256.

18. Attard G, Belldegrun AS, de Bono JS. Selective blockade of androgenic steroid synthesis by novel lyase inhibitors as a therapeutic strategy for treating metastatic prostate cancer. BJU Int 2005;96:1241-1246.

19. Tran C, Ouk S, Clegg NJ, et al. Development of a second-generation antiandrogen for treatment of advanced prostate cancer. Science 2009;324:787-790.

20. Clegg NJ, Wongvipat J, Joseph JD, et al. ARN-509: a novel antiandrogen for prostate cancer treatment. Cancer Res 2012;72:1494-1503.

21. Fizazi K, Tran N, Fein L, et al. Abiraterone plus prednisone in metastatic, castration-sensitive prostate cancer. $\mathrm{N}$ Engl J Med 2017;377:352-360.

22. Fizazi K, Tran N, Fein L, et al. Abiraterone acetate plus prednisone in patients with newly diagnosed high-risk metastatic castration-sensitive prostate cancer (LATITUDE): final overall survival analysis of a randomised, double-blind, phase 3 trial. Lancet Oncol 2019;20:686-700.

23. James ND, de Bono JS, Spears MR, et al. Abiraterone for prostate cancer not previously treated with hormone therapy. N Engl J Med 2017;377:338-351.

24. Hoyle AP, Ali A, James ND, et al. Abiraterone in "high-" and "low-risk" metastatic hormone-sensitive prostate cancer. Eur Urol 2019;76:719-728.

25. Davis ID, Martin AJ, Stockler MR, et al. Enzalutamide with standard first-line therapy in metastatic prostate cancer. N Engl J Med 2019;381:121-131.

26. Armstrong AJ, Szmulewitz RZ, Petrylak DP, et al. ARCHES: a randomized, phase III study of androgen deprivation therapy with enzalutamide or placebo in men with metastatic hormone-sensitive prostate cancer. J Clin Oncol 2019;37:2974-2986.

27. Chi KN, Agarwal N, Bjartell A, et al. Apalutamide for metastatic, castration-sensitive prostate cancer. N Engl J Med 2019;381:13-24.

28. Studer UE, Whelan P, Albrecht W, et al. Immediate or deferred androgen deprivation for patients with prostate cancer not suitable for local treatment with curative intent: European Organisation for Research and Treatment of Cancer (EORTC) Trial 30891. J Clin Oncol 2006;24:18681876.

29. Kirk D. Timing and choice of androgen ablation. Prostate Cancer Prostatic Dis 2004;7:217-222.

30. Studer UE, Hauri D, Hanselmann S, et al. Immediate versus deferred hormonal treatment for patients with prostate cancer who are not suitable for curative local treatment: results of the randomized trial SAKK 08/88. J Clin Oncol 2004;22:4109-4118.

31. Scher HI, Halabi S, Tannock I, et al. Design and end points of clinical trials for patients with progressive prostate cancer and castrate levels of testosterone: recommendations of the Prostate Cancer Clinical Trials Working Group. J 
Clin Oncol 2008;26:1148-1159.

32. Eisenhauer EA, Therasse P, Bogaerts J, et al. New response evaluation criteria in solid tumours: revised RECIST guideline (version 1.1). Eur J Cancer 2009;45:228-247.

33. Schwartz LH, Seymour L, Litiere S, et al. RECIST 1.1. Standardisation and disease-specific adaptations: perspectives from the RECIST Working Group. Eur J Cancer 2016;62:138-145.

34. Leone G, Tucci M, Buttigliero C, et al. Antiandrogen withdrawal syndrome (AAWS) in the treatment of patients with prostate cancer. Endocr Relat Cancer 2018;25:R1-R9.

35. Ryan CJ, Smith MR, de Bono JS, et al. Abiraterone in metastatic prostate cancer without previous chemotherapy. N Engl J Med 2013;368:138-148.

36. Basch E, Autio K, Ryan CJ, et al. Abiraterone acetate plus prednisone versus prednisone alone in chemotherapy-naive men with metastatic castration-resistant prostate cancer: patient-reported outcome results of a randomised phase 3 trial. Lancet Oncol 2013;14:1193-1199.

37. Beer TM, Armstrong AJ, Rathkopf DE, et al. Enzalutamide in metastatic prostate cancer before chemotherapy. N Engl J Med 2014;371:424-433.

38. de Bono JS, Logothetis CJ, Molina A, et al. Abiraterone and increased survival in metastatic prostate cancer. $\mathrm{N}$ Engl J Med 2011;364:1995-2005.

39. Fizazi K, Scher HI, Molina A, et al. Abiraterone acetate for treatment of metastatic castration-resistant prostate cancer: final overall survival analysis of the COU-AA-301 randomised, double-blind, placebo-controlled phase 3 study. Lancet Oncol 2012;13:983-992.

40. Scher HI, Fizazi K, Saad F, et al. Increased survival with enzalutamide in prostate cancer after chemotherapy. N Engl J Med 2012;367:1187-1197.

41. Graff JN, Baciarello G, Armstrong AJ, et al. Efficacy and safety of enzalutamide in patients 75 years or older with chemotherapy-naive metastatic castration-resistant prostate cancer: results from PREVAIL. Ann Oncol 2016;27:286-294.

42. Tannock IF, de Wit R, Berry WR, et al. Docetaxel plus prednisone or mitoxantrone plus prednisone for advanced prostate cancer. N Engl J Med 2004;351:1502-1512.

43. Berthold DR, Pond GR, Soban F, de Wit R, Eisenberger M, Tannock IF. Docetaxel plus prednisone or mitoxantrone plus prednisone for advanced prostate cancer: updated survival in the TAX 327 study. J Clin Oncol 2008;26:242245 .
44. Kellokumpu-Lehtinen PL, Harmenberg U, Joensuu T, et al. 2-Weekly versus 3-weekly docetaxel to treat castration-resistant advanced prostate cancer: a randomised, phase 3 trial. Lancet Oncol 2013;14:117-124.

45. de Bono JS, Oudard S, Ozguroglu M, et al. Prednisone plus cabazitaxel or mitoxantrone for metastatic castration-resistant prostate cancer progressing after docetaxel treatment: a randomised open-label trial. Lancet 2010;376:1147-1154.

46. Eisenberger M, Hardy-Bessard AC, Kim CS, et al. Phase III study comparing a reduced dose of cabazitaxel (20 mg/ $\left.\mathrm{m}^{2}\right)$ and the currently approved dose $\left(25 \mathrm{mg} / \mathrm{m}^{2}\right)$ in postdocetaxel patients with metastatic castration-resistant prostate cancer-PROSELICA. J Clin Oncol 2017;35:31983206.

47. Oudard S, Fizazi K, Sengelov L, et al. Cabazitaxel versus docetaxel as first-line therapy for patients with metastatic castration-resistant prostate cancer: a randomized phase III trial-FIRSTANA. J Clin Oncol 2017;35:3189-3197.

48. de Wit R, de Bono J, Sternberg CN, et al. Cabazitaxel versus abiraterone or enzalutamide in metastatic prostate cancer. N Engl J Med 2019;381:2506-2518.

49. Parker C, Nilsson S, Heinrich D, et al. Alpha emitter radium-223 and survival in metastatic prostate cancer. N Engl J Med 2013;369:213-223.

50. Smith M, Parker C, Saad F, et al. Addition of radium-223 to abiraterone acetate and prednisone or prednisolone in patients with castration-resistant prostate cancer and bone metastases (ERA 223): a randomised, double-blind, placebo-controlled, phase 3 trial. Lancet Oncol 2019;20:408-419.

51. Mullane SA, Van Allen EM. Precision medicine for advanced prostate cancer. Curr Opin Urol 2016;26:231-239.

52. Cancer Genome Atlas Research Network. The molecular taxonomy of primary prostate cancer. Cell 2015;163:10111125 .

53. Castro E, Goh C, Olmos D, et al. Germline BRCA mutations are associated with higher risk of nodal involvement, distant metastasis, and poor survival outcomes in prostate cancer. J Clin Oncol 2013;31:1748-1757.

54. Mateo J, Boysen G, Barbieri CE, et al. DNA repair in prostate cancer: biology and clinical implications. Eur Urol 2017;71:417-425.

55. Mateo J, Carreira S, Sandhu S, et al. DNA-repair defects and olaparib in metastatic prostate cancer. N Engl J Med 2015;373:1697-1708. 
56. Mateo J, Porta N, Bianchini D, et al. Olaparib in patients with metastatic castration-resistant prostate cancer with DNA repair gene aberrations (TOPARP-B): a multicentre, open-label, randomised, phase 2 trial. Lancet Oncol 2020;21:162-174.

57. de Bono J, Mateo J, Fizazi K, et al. Olaparib for metastatic castration-resistant prostate cancer. N Engl J Med 2020;382:2091-2102.

58. Beer TM, Kwon ED, Drake CG, et al. Randomized, double-blind, phase III trial of ipilimumab versus placebo in asymptomatic or minimally symptomatic patients with metastatic chemotherapy-naive castration-resistant prostate cancer. J Clin Oncol 2017;35:40-47.

59. Hansen AR, Massard C, Ott PA, et al. Pembrolizumab for advanced prostate adenocarcinoma: findings of the KEYNOTE-o28 study. Ann Oncol 2018;29:1807-1813.

6o. Antonarakis ES, Piulats JM, Gross-Goupil M, et al. Pembrolizumab for treatment-refractory metastatic castration-resistant prostate cancer: multicohort, open-label phase II KEYNOTE-199 study. J Clin Oncol 2020;38:395405 .

61. El-Amm J, Aragon-Ching JB. The current landscape of treatment in non-metastatic castration-resistant prostate cancer. Clin Med Insights Oncol 2019;13:1179554919833927.

62. Smith MR, Saad F, Oudard S, et al. Denosumab and bone metastasis-free survival in men with nonmetastatic castration-resistant prostate cancer: exploratory analyses by baseline prostate- specific antigen doubling time. J Clin Oncol 2013;31:3800-3806.

63. Smith MR, Kabbinavar F, Saad F, et al. Natural history of rising serum prostate-specific antigen in men with castrate nonmetastatic prostate cancer. J Clin Oncol 2005;23:2918-2925.

64. Smith MR, Saad F, Chowdhury S, et al. Apalutamide treatment and metastasis-free survival in prostate cancer. $\mathrm{N}$ Engl J Med 2018;378:1408-1418.

65. Hussain M, Fizazi K, Saad F, et al. Enzalutamide in men with nonmetastatic, castration-resistant prostate cancer. N Engl J Med 2018;378:2465-2474.

66. Fizazi K, Shore N, Tammela TL, et al. Darolutamide in nonmetastatic, castration-resistant prostate cancer. N Engl J Med 2019;380:1235-1246.

67. de Morree ES, Vogelzang NJ, Petrylak DP, et al. Association of survival benefit with docetaxel in prostate cancer and total number of cycles administered: a post hoc analysis of the mainsail study. JAMA Oncol 2017;3:68-75.
68. de Bono JS, Smith MR, Saad F, et al. Subsequent chemotherapy and treatment patterns after abiraterone acetate in patients with metastatic castration-resistant prostate cancer: post hoc analysis of COU-AA-302. Eur Urol 2017;71:656-664.

69. Khalaf DJ, Annala M, Taavitsainen S, et al. Optimal sequencing of enzalutamide and abiraterone acetate plus prednisone in metastatic castration-resistant prostate cancer: a multicentre, randomised, open-label, phase 2 , crossover trial. Lancet Oncol 2019;20:1730-1739.

70. Lavaud P, Gravis G, Foulon S, et al. Anticancer activity and tolerance of treatments received beyond progression in men treated upfront with androgen deprivation therapy with or without docetaxel for metastatic castration-naive prostate cancer in the GETUG-AFU 15 phase 3 trial. Eur Urol 2018;73:696-703.

71. Mountzios I, Bournakis E, Efstathiou E, et al. Intermittent docetaxel chemotherapy in patients with castrate-resistant prostate cancer. Urology 2011;77:682-687.

72. Caffo O, Pappagallo G, Brugnara S, et al. Multiple rechallenges for castration-resistant prostate cancer patients responding to first-line docetaxel: assessment of clinical outcomes and predictive factors. Urology 2012;79:644-649.

73. Di Lorenzo G, Buonerba C, Faiella A, et al. Phase II study of docetaxel re-treatment in docetaxel-pretreated castration-resistant prostate cancer. BJU Int 2011;107:234-239.

74. Scher HI, Morris MJ, Kelly WK, Schwartz LH, Heller G. Prostate cancer clinical trial end points: "RECIST"ing a step backwards. Clin Cancer Res 2005;11:5223-5232.

75. Saad F, Gleason DM, Murray R, et al. A randomized, placebo-controlled trial of zoledronic acid in patients with hormone-refractory metastatic prostate carcinoma. J Natl Cancer Inst 2002;94:1458-1468.

76. Saad F, Gleason DM, Murray R, et al. Long-term efficacy of zoledronic acid for the prevention of skeletal complications in patients with metastatic hormone-refractory prostate cancer. J Natl Cancer Inst 2004;96:879-882.

77. Small EJ, Smith MR, Seaman JJ, Petrone S, Kowalski MO. Combined analysis of two multicenter, randomized, placebo-controlled studies of pamidronate disodium for the palliation of bone pain in men with metastatic prostate cancer. J Clin Oncol 2003;21:4277-4284.

78. Ernst DS, Tannock IF, Winquist EW, et al. Randomized, double-blind, controlled trial of mitoxantrone/prednisone and clodronate versus mitoxantrone/prednisone and placebo in patients with hormone-refractory prostate 
cancer and pain. J Clin Oncol 2003;21:3335-3342.

79. Fizazi K, Carducci M, Smith M, et al. Denosumab versus zoledronic acid for treatment of bone metastases in men with castration- resistant prostate cancer: a randomised, double-blind study. Lancet 2011;377:813-822.

8o. Smith MR, Halabi S, Ryan CJ, et al. Randomized controlled trial of early zoledronic acid in men with castration-sensitive prostate cancer and bone metastases: results of CALGB 90202 (alliance). J Clin Oncol 2014;32:11431150.

81. Kamba T, Kamoto T, Maruo S, et al. A phase III multicenter, randomized, controlled study of combined androgen blockade with versus without zoledronic acid in prostate cancer patients with metastatic bone disease: results of the ZAPCA trial. Int J Clin Oncol 2017;22:166173.

82. Droz JP, Aapro M, Balducci L, et al. Management of prostate cancer in older patients: updated recommendations of a working group of the International Society of Geriatric Oncology. Lancet Oncol 2014;15:e404-e414.

83. Horwich A, Parker C, de Reijke T, Kataja V; ESMO Guidelines Working Group. Prostate cancer: ESMO clinical practice guidelines for diagnosis, treatment and follow-up. Ann Oncol 2013;24 Suppl 6:vi1o6-vin14.

84. Body JJ, Bone HG, de Boer RH, et al. Hypocalcaemia in patients with metastatic bone disease treated with denosumab. Eur J Cancer 2015;51:1812-1821.

85. Bienz M, Saad F. Androgen-deprivation therapy and bone loss in prostate cancer patients: a clinical review. Bonekey Rep 2015;4:716.

86. Smith MR, Boyce SP, Moyneur E, Duh MS, Raut MK, Brandman J. Risk of clinical fractures after gonadotropin-releasing hormone agonist therapy for prostate cancer. J Urol 2006;175:136-139.

87. Shahinian VB, Kuo YF, Freeman JL, Goodwin JS. Risk of fracture after androgen deprivation for prostate cancer. N Engl J Med 2005;352:154-164.

88. Michaelson MD, Kaufman DS, Lee H, et al. Randomized controlled trial of annual zoledronic acid to prevent gonadotropin-releasing hormone agonist-induced bone loss in men with prostate cancer. J Clin Oncol 2007;25:1038-1042.

89. Greenspan SL, Nelson JB, Trump DL, Resnick NM. Effect of once-weekly oral alendronate on bone loss in men receiving androgen deprivation therapy for prostate cancer: a randomized trial. Ann Intern Med 2007;146:416-424.
90. Smith MR, Egerdie B, Hernandez Toriz N, et al. Denosumab in men receiving androgen-deprivation therapy for prostate cancer. N Engl J Med 2009;361:745-755.

91. Lutz S. The role of radiation therapy in controlling painful bone metastases. Curr Pain Headache Rep 2012;16:300306.

92. Goblirsch MJ, Zwolak PP, Clohisy DR. Biology of bone cancer pain. Clin Cancer Res 2006;12:6231s-6235s.

93. Vakaet LA, Boterberg T. Pain control by ionizing radiation of bone metastasis. Int J Dev Biol 2004;48:599-606.

94. Hartsell WF, Scott CB, Bruner DW, et al. Randomized trial of short- versus long-course radiotherapy for palliation of painful bone metastases. J Natl Cancer Inst 2005;97:798804 .

95. Chow E, van der Linden YM, Roos D, et al. Single versus multiple fractions of repeat radiation for painful bone metastases: a randomised, controlled, non-inferiority trial. Lancet Oncol 2014;15:164-171.

96. Chow E, Zeng L, Salvo N, Dennis K, Tsao M, Lutz S. Update on the systematic review of palliative radiotherapy trials for bone metastases. Clin Oncol (R Coll Radiol) 2012;24:112-124.

97. Huisman M, van den Bosch MA, Wijlemans JW, van Vulpen $M$, van der Linden YM, Verkooijen HM. Effectiveness of reirradiation for painful bone metastases: a systematic review and meta-analysis. Int J Radiat Oncol Biol Phys 2012;84:8-14.

98. Holzbeierlein JM, McLaughlin MD, Thrasher JB. Complications of androgen deprivation therapy for prostate cancer. Curr Opin Urol 2004;14:177-183.

99. Elliott S, Latini DM, Walker LM, Wassersug R, Robinson JW; ADT Survivorship Working Group. Androgen deprivation therapy for prostate cancer: recommendations to improve patient and partner quality of life. J Sex Med 2010;7:2996-3010.

100. de Voogt HJ, Smith PH, Pavone-Macaluso M, de Pauw M, Suciu S. Cardiovascular side effects of diethylstilbestrol, cyproterone acetate, medroxyprogesterone acetate and estramustine phosphate used for the treatment of advanced prostatic cancer: results from European Organization for Research on Treatment of Cancer trials 30761 and 30762. J Urol 1986;135:303-307.

101. Tunio MA, Al-Asiri M, Al-Amro A, Bayoumi Y, Fareed M. Optimal prophylactic and definitive therapy for bicalutamide-induced gynecomastia: results of a meta-analysis. Curr Oncol 2012;19:e280-e288. 
102. Viani GA, Bernardes da Silva LG, Stefano EJ. Prevention of gynecomastia and breast pain caused by androgen deprivation therapy in prostate cancer: tamoxifen or radiotherapy? Int J Radiat Oncol Biol Phys 2012;83:e519-e524.

103. Lu-Yao G, Stukel TA, Yao SL. Changing patterns in competing causes of death in men with prostate cancer: a population based study. J Urol 2004;171:2285-2290.

104. O'Farrell S, Garmo H, Holmberg L, Adolfsson J, Stattin P, Van Hemelrijck M. Risk and timing of cardiovascular disease after androgen-deprivation therapy in men with prostate cancer. J Clin Oncol 2015;33:1243-1251.

105. Saigal CS, Gore JL, Krupski TL, et al. Androgen deprivation therapy increases cardiovascular morbidity in men with prostate cancer. Cancer 2007;110:1493-1500.

106. Bosco C, Bosnyak Z, Malmberg A, Adolfsson J, Keating NL, Van Hemelrijck M. Quantifying observational evidence for risk of fatal and nonfatal cardiovascular disease following androgen deprivation therapy for prostate cancer: a meta-analysis. Eur Urol 2015;68:386-396.

107. Keating NL, O'Malley AJ, Smith MR. Diabetes and cardiovascular disease during androgen deprivation therapy for prostate cancer. J Clin Oncol 2006;24:4448-4456.

108. D'Amico AV, Denham JW, Crook J, et al. Influence of androgen suppression therapy for prostate cancer on the frequency and timing of fatal myocardial infarctions. J Clin Oncol 2007;25:2420-2425.

109. Efstathiou JA, Bae K, Shipley WU, et al. Cardiovascular mortality after androgen deprivation therapy for locally advanced prostate cancer: RTOG 85-31. J Clin Oncol 2009;27:92-99.

110. Nguyen PL, Je Y, Schutz FA, et al. Association of androgen deprivation therapy with cardiovascular death in patients with prostate cancer: a meta-analysis of randomized trials. JAMA 2011;306:2359-2366.

111. Roach M 3rd, Bae K, Speight J, et al. Short-term neoadjuvant androgen deprivation therapy and external-beam radiotherapy for locally advanced prostate cancer: longterm results of RTOG 8610. J Clin Oncol 2008;26:585-591.

112. Tsai HK, D'Amico AV, Sadetsky N, Chen MH, Carroll PR. Androgen deprivation therapy for localized prostate cancer and the risk of cardiovascular mortality. J Natl Cancer Inst 2007;99:1516-1524.

113. Voog JC, Paulus R, Shipley WU, et al. Cardiovascular mortality following short-term androgen deprivation in clinically localized prostate cancer: an analysis of RTOG 94-08. Eur Urol 2016;69:204-210.
114. Wilcox C, Kautto A, Steigler A, Denham JW. Androgen deprivation therapy for prostate cancer does not increase cardiovascular mortality in the long term. Oncology 2012;82:56-58.

115. D'Amico AV, Chen MH, Renshaw A, Loffredo M, Kantoff PW. Long-term follow-up of a randomized trial of radiation with or without androgen deprivation therapy for localized prostate cancer. JAMA 2015;314:1291-1293.

116. Levine GN, D'Amico AV, Berger P, et al. Androgen-deprivation therapy in prostate cancer and cardiovascular risk: a science advisory from the American Heart Association, American Cancer Society, and American Urological Association: endorsed by the American Society for Radiation Oncology. Circulation 2010;121:833-840.

117. Guan J, Khambhati J, Jones LW, et al. Cardiology patient page: ABCDE steps for heart and vascular wellness following a prostate cancer diagnosis. Circulation 2015;132:e218-e220.

118. Shahinian VB, Kuo YF, Freeman JL, Goodwin JS. Risk of the "androgen deprivation syndrome" in men receiving androgen deprivation for prostate cancer. Arch Intern Med 2006;166:465-471.

119. Nead KT, Gaskin G, Chester C, Swisher-McClure S, Leeper NJ, Shah NH. Association between androgen deprivation therapy and risk of dementia. JAMA Oncol 2017;3:4955 .

120. Alibhai SM, Breunis H, Timilshina N, et al. Impact of androgen-deprivation therapy on cognitive function in men with nonmetastatic prostate cancer. J Clin Oncol 2010;28:5030-5037.

121. Cherrier MM, Asthana S, Plymate S, et al. Testosterone supplementation improves spatial and verbal memory in healthy older men. Neurology 2001;57:80-88.

122. Green HJ, Pakenham KI, Headley BC, et al. Altered cognitive function in men treated for prostate cancer with luteinizing hormone-releasing hormone analogues and cyproterone acetate: a randomized controlled trial. BJU Int 2002;90:427-432.

123. Sun M, Cole AP, Hanna N, et al. Cognitive impairment in men with prostate cancer treated with androgen deprivation therapy: a systematic review and meta-analysis. J Urol 2018;199:1417-1425.

124. Yang J, Zhong F, Qiu J, Cheng H, Wang K. Dissociation of event-based prospective memory and time-based prospective memory in patients with prostate cancer receiving androgen-deprivation therapy: a neuropsychological 
study. Eur J Cancer Care (Engl) 2015;24:198-204.

125. Hirano D, Okada Y, Minei S, Takimoto Y, Nemoto N. Neuroendocrine differentiation in hormone refractory prostate cancer following androgen deprivation therapy. Eur Urol 2004;45:586-592.

126. Ismail A HR, Landry F, Aprikian AG, Chevalier S. Androgen ablation promotes neuroendocrine cell differentiation in dog and human prostate. Prostate 2002;51:117-125.

127. Nadal R, Schweizer M, Kryvenko ON, Epstein JI, Eisenberger MA. Small cell carcinoma of the prostate. Nat Rev Urol 2014;11:213-219.

128. Wang HT, Yao YH, Li BG, Tang Y, Chang JW, Zhang J. Neuroendocrine Prostate Cancer (NEPC) progressing from conventional prostatic adenocarcinoma: factors associated with time to development of NEPC and survival from NEPC diagnosis-a systematic review and pooled analysis. J Clin Oncol 2014;32:3383-3390.

129. Aggarwal R, Huang J, Alumkal JJ, et al. Clinical and genomic characterization of treatment-emergent small-cell neuroendocrine prostate cancer: a multi-institutional prospective study. J Clin Oncol 2018;36:2492-2503.

130. Yao JL, Madeb R, Bourne P, et al. Small cell carcinoma of the prostate: an immunohistochemical study. Am J Surg Pathol 2006;30:705-712.

131. Spiess PE, Pettaway CA, Vakar-Lopez F, et al. Treatment outcomes of small cell carcinoma of the prostate: a single-center study. Cancer 2007;110:1729-1737.

132. Corn PG, Heath EI, Zurita A, et al. Cabazitaxel plus carboplatin for the treatment of men with metastatic castration-resistant prostate cancers: a randomised, open-label, phase 1-2 trial. Lancet Oncol 2019;20:1432-1443. 